\title{
Pheno- and Genotyping of Hopanoid Production in Acidobacteria
}

\author{
Jaap S. Sinninghe Damsté ${ }^{1,2 *}$, W. Irene C. Rijpstra ${ }^{1}$, Svetlana N. Dedysh ${ }^{3}$, \\ Bärbel U. Foesel ${ }^{4}$ and Laura Villanueva ${ }^{1}$
}

${ }^{1}$ Department of Marine Microbiology and Biogeochemistry, NIOZ Royal Netherlands Institute for Sea Research, Utrecht University, Den Burg, Netherlands, ${ }^{2}$ Department of Earth Sciences, Geochemistry, Faculty of Geosciences, Utrecht University, Utrecht, Netherlands, ${ }^{3}$ S. N. Winogradsky Institute of Microbiology, Research Center of Biotechnology of Russian Academy of Sciences, Moscow, Russia, ${ }^{4}$ Department of Microbial Ecology and Diversity Research, German Collection of Microorganisms and Cell Cultures (LG), Braunschweig, Germany

\section{OPEN ACCESS}

Edited by:

Martin G. Klotz,

Queens College (CUNY),

United States

Reviewed by:

Paula V. Welander,

Stanford University, United States

Christian Sohlenkamp,

National Autonomous University of

Mexico, Mexico

*Correspondence:

Jaap S. Sinninghe Damsté

jaap.damste@nioz.nl

Specialty section:

This article was submitted to

Microbiological Chemistry and

Geomicrobiology,

a section of the journal

Frontiers in Microbiology

Received: 28 March 2017

Accepted: 15 May 2017

Published: 08 June 2017

Citation:

Damsté JSS, Rijpstra WIC,

Dedysh SN, Foesel BU and

Villanueva L (2017) Pheno- and Genotyping of Hopanoid Production in Acidobacteria. Front. Microbiol. 8:968. doi: 10.3389/fmicb.2017.00968
Hopanoids are pentacyclic triterpenoid lipids synthesized by different bacterial groups. Methylated hopanoids were believed to be exclusively synthesized by cyanobacteria and aerobic methanotrophs until the genes encoding for the methylation at the C-2 and C-3 position ( $h p n \mathrm{P}$ and $h p n \mathrm{R}$ ) were found to be widespread in the bacterial domain, invalidating their use as specific biomarkers. These genes have been detected in the genome of the Acidobacterium "Ca. Koribacter versatilis," but our knowledge of the synthesis of hopanoids and the presence of genes of their biosynthetic pathway in other member of the Acidobacteria is limited. We analyzed 38 different strains of seven Acidobacteria subdivisions (SDs 1, 3, 4, 6, 8, 10, and 23) for the presence of $\mathrm{C}_{30}$ hopenes and $\mathrm{C}_{30}$ bacteriohopane polyols (BHPs) using the Rohmer reaction. BHPs and/or $\mathrm{C}_{30}$ hopenes were detected in all strains of SD1 and SD3 but not in SD4 (excepting Chloracidobacterium thermophilum), 6, 8, 10, and 23. This is in good agreement with the presence of genes required for hopanoid biosynthesis in the 31 available whole genomes of cultivated Acidobacteria. All genomes encode the enzymes involved in the non-mevalonate pathway ultimately leading to farnesyl diphosphate but only SD1 and 3 Acidobacteria and C. thermophilum encode all three enzymes required for the synthesis of squalene, its cyclization (shc), and addition and modification of the extended side chain (hpnG, hpnH, hpnl, hpnJ, hpnO). In almost all strains, only tetrafunctionalized BHPs were detected; three strains contained variable relative abundances (up to $45 \%$ ) of pentafunctionalized BHPs. Only "Ca. K. versatilis" contained methylated hopanoids (i.e., 2,3-dimethyl bishomohopanol), although in low (<10\%) amounts. These genes are not present in any other Acidobacterium, consistent with the absence of methylated BHPs in the other examined strains. These data are in agreement with the scattered occurrence of methylated BHPs in other bacterial phyla such as the Alpha-, Beta-, and Gammaproteobacteria and the Cyanobacteria, limiting their biomarker potential. Metagenomes of Acidobacteria were also examined for the presence of genes required for hopanoid biosynthesis. The complete pathway for BHP biosynthesis was evident in SD2 Acidobacteria and a group phylogenetically related to SD1 and SD3, in line with the limited occurrence of BHPs in acidobacterial cultures.

Keywords: Hopanoids, Acidobacteria, lipid biosynthesis, lipid analysis, methylation, genomes, metagenomes 


\section{INTRODUCTION}

Hopanoids are omnipresent natural products occurring in many groups of bacteria and some higher plants. The recognition of their widespread occurrence in the bacterial domain was initiated by the ubiquitous presence of molecular fossils derived from hopanoids in the geological record (Ourisson et al., 1979). Hopanoids occur in a variety of structures from relatively simple $\mathrm{C}_{30}$ components to elongated compounds with a polyfunctionalized side chain, i.e., the bacteriohopanepolyols (BHPs), often containing additional substituents, i.e., the socalled BHP derivatives (see for reviews Kannenberg and Poralla, 1999 and Rezanka et al., 2010).

The large variety in structure and their ubiquitous presence in sediments and petroleum has resulted in the common application of hopanoids as molecular fossils. For example, the occurrence of hopanoids methylated at the C-2 position in the A-ring of hopanoids were thought to be limited to cyanobacteria. Consequently, their fossil occurrence has been used to reveal the timing of the advent of oxygenic photosynthesis (Summons et al., 1999). The abundance of 2-methyl extended hopanes relative to their non-methylated counterparts was used to conclude that nitrogen-fixing cyanobacteria played a key role in the deposition of black shales during the early Aptian and late Cenomanian oceanic anoxic events (Kuypers et al., 2004). Such studies strongly rely on the consistency of the link between cyanobacteria and their unique ability to produce 2-methyl BHPs. This link was already somewhat questionable since non-extended 2-methyl hopanoids (i.e., $2 ß$-methyldiplopterol and $2 ß$-methyldiploptene) were also reported in species falling in the group of the Alphaproteobacteria (Zundel and Rohmer, 1985; Knani et al., 1994; Vilcheze et al., 1994; Bravo et al., 2001). Subsequently, an extended 2-methyl hopanoid was detected in the anoxygenic phototroph, Rhodopseudomonas palustris (Rashby et al., 2007), also belonging to the Alphaproteobacteria. This revealed that the potential origins of sedimentary extended 2-methyl hopanoids are more diverse than previously thought.

This example highlights the importance of studies of lipids in cultured microbes for our interpretation of the molecular fossil record. However, such studies are laborious and have therefore been limited in number. Furthermore, they are fundamentally biased by the fact that the majority of the environmentally significant microbes are not available in culture. One approach to solve these issues is to use the genetic information of microbes that encodes the biochemical machinery of the cell, including their lipid biosynthetic pathways. Applying this approach in hopanoid research, Pearson et al. $(2007,2009)$ investigated the gene encoding the squalene-hopene cyclase $(s h c)$, which represents the first step in BHP biosynthesis, to search in the environment for potential producers of BHPs. Welander et al. (2010) also used a genetic approach and identified a radical SAM methylase encoded by a gene $(h p n P)$ that is required for the methylation of hopanoids at the C-2 position. They demonstrated that this $h p n P$ gene is not only present in cyanobacteria, but also in Alphaproteobacteria and Acidobacteria, casting further doubt on the application of 2-methyl BHPs as indicators for cyanobacteria. In a follow-up paper (Ricci et al., 2014) they used this gene to search for potential sources of 2-methyl hopanoids and reported environmental $h p n P$ genes for cyanobacteria, alpha proteobacteria, but not for acidobacteria. Welander and Summons (2012) showed that a gene, $h p n R$, is required for methylation of hopanoids at the C-3 position in Methylococcus capsulatus. This gene is found in genomes of methanotrophic and acetic acid bacteria but also in other bacteria such as Actinobacteria, Nitrospirae, and Acidobacteria and, consequently, 3-methyl hopanoids cannot be used as biomarkers for aerobic methanotrophs.

Acidobacteria are a highly abundant and diverse phylum of the domain Bacteria (e.g., Dedysh et al., 2006; Janssen, 2006; Jones et al., 2009) and, therefore, could potentially be important sources for 2- and 3-methyl BHPs in the environment. The phylogenetic breadth of the Acidobacteria is comparable to that of the Proteobacteria (see Kielak et al., 2016 for a recent review). They have been divided in 26 subdivisions (SDs), mainly based on environmental sequences (Barns et al., 2007), but only seven of these contain taxonomically characterized representatives (Kielak et al., 2016). For SD1, eleven genera have been defined, and for SD4 eight genera, while a more limited number of genera (1-4 genera) have been characterized for SDs 3, 6, 8, 10, and 23. All cultured acidobacteria are heterotrophic and are able to grow on a variety of substrates. Molecular ecological studies have revealed that, in wetlands, the most abundant Acidobacteria fall in SD1 and 3 (Serkebaeva et al., 2013), whereas in lakes SDs 1, 6, and 7 thrive (Zimmermann et al., 2012). In soils, SDs 14 and 6 are most abundant (Jones et al., 2009). The hopanoids produced by Acidobacteria may thus form a major source of hopanoids in the environment. Since Welander et al. (2010) and Welander and Summons (2012) detected the shc gene and two genes involved in the methylation of hopanoids at the C2 and the C-3 position in "Candidatus Koribacter versatilis," an SD1 acidobacterium isolated from soil (Joseph et al., 2003) for which the whole genome is available (Ward et al., 2009), we cultivated "Ca. K. versatilis" and 37 other acidobacterial strains of SDs $1,3,4,6,8,10$, and 23 in order to test if Acidobacteria can indeed be an important source of specific hopanoids in the environment. We compared these results with the presence of genes involved in the biosynthetic pathway leading to BHPs.

\section{MATERIALS AND METHODS}

\section{Cultures}

The acidobacterial strains used in this study are listed in Table 1 and mostly were cultivated under conditions previously described (Sinninghe Damsté et al., 2011, 2014). “Ca. Koribacter versatilis Ellin345” (DSM 22529) and “Ca. Solibacter usitatus Ellin6076" (DSM 22595) were cultivated at $25^{\circ} \mathrm{C}$ in VL55 media, Geothrix fermentans (DSM 14018) was grown at $32^{\circ} \mathrm{C}$ in Geobacter medium (M 826, DSMZ media list) and Holophaga foetida (DSM 6591) at $28^{\circ} \mathrm{C}$ in TMBS4 medium (M 559 from DSMZ media list). The two species of SD6 Acidobacteria were grown as described earlier (Huber et al., 2016; Vieira et al., 2017).

\section{Lipid Analysis}

For the detection of the presence of biohopanoids, lyophilized cells were directly treated with periodic acid/sodium borohydride 
TABLE 1 | Presence of BHPs (both penta- and tetrafunctionalized in \%) and hop-17(21)-ene in cultivated Acidobacteria of SDs 1, 3, 4, 6, 8, 10 , and 23.

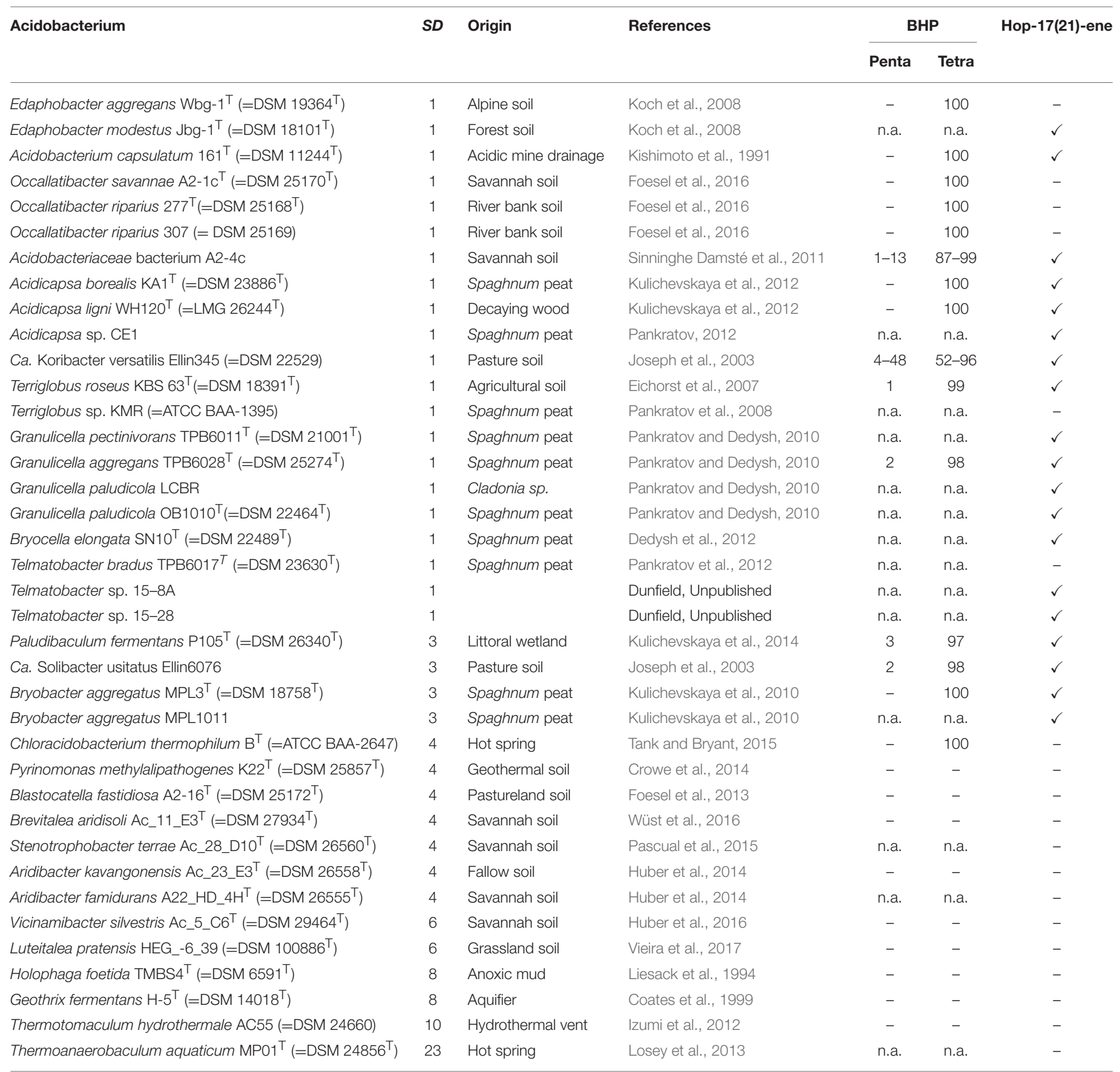

-, Absent; n.a. $=$ not analyzed, $\checkmark$, present.

to convert polyfunctionalized biohopanoids into GC-amenable hopanoid alcohols following procedure 2 described by Rohmer et al. (1984) with some modifications. Lyophilized cells (ca. $10 \mathrm{mg}$ ) were stirred with $1 \mathrm{ml}$ of a solution of periodic acid $(30 \mathrm{mg})$ in tetrahydrofuran/water $(8: 1, \mathrm{v} / \mathrm{v})$ at room temperature for $1 \mathrm{~h}$. After addition of water $(1 \mathrm{ml})$, the lipids were extracted three times with dichloromethane (DCM; $2 \mathrm{ml}$ ), and the solution was dried over anhydrous $\mathrm{Na}_{2} \mathrm{SO}_{4}$, and evaporated to dryness. The residue was treated with $20 \mathrm{mg}$ of $\mathrm{NaBH}_{4}(100 \mathrm{mg})$, in $1 \mathrm{ml}$ methanol by stirring at room temperature for $1 \mathrm{~h}$.
After addition of a solution of $\mathrm{KH}_{2} \mathrm{PO}_{4}(1 \mathrm{ml}, 200 \mathrm{mM})$, the hopanols were extracted with DCM. The obtained reaction mixture was methylated with diazomethane and separated over a small column with activated $\mathrm{Al}_{2} \mathrm{O}_{3}$ into an apolar and a polar fraction using DCM and DCM-MeOH $(2: 1, \mathrm{v} / \mathrm{v})$ as eluent, respectively. The polar fractions were silylated with $\mathrm{N}, \mathrm{O}$-bis(trimethylsilyl)-fluoroacetamide in pyridine at $60^{\circ} \mathrm{C}$ for $20 \mathrm{~min}$ and analyzed by GC and GC-MS. The distribution of hopanols was obtained by integration of the appropriate peaks. 
The lyophilized cells of strain A2-4c were also extracted ultrasonically with $\mathrm{DCM} / \mathrm{MeOH}(2: 1, \mathrm{v} / \mathrm{v})(\times 3)$ and the extract was subsequently subjected to the Rohmer degradation to compare the yield of the generation of hopanols from the extract as compared to direct treatment of the cell material. To this end, an internal standard (6,6- $\mathrm{d}_{2}$-3-methylheneicosane) was added to quantify the hopanols for the two different ways of treatment.

GC was performed using a Hewlett-Packard 6890 instrument, equipped with an on-column injector. A fused silica capillary column $(25 \mathrm{~m} \times 0.32 \mathrm{~mm})$ coated with CP-Sil 5 (film thickness $0.12 \mu \mathrm{m}$ ) was used with helium as carrier gas. Samples were dissolved in ethyl acetate and injected at $70^{\circ} \mathrm{C}$ and the oven was programmed to $130^{\circ} \mathrm{C}$ at $20^{\circ} \mathrm{C} / \mathrm{min}$ and then at $4^{\circ} \mathrm{C} / \mathrm{min}$ to $320^{\circ} \mathrm{C}$ at which it was held for $10 \mathrm{~min}$. GC-MS analyses were performed on a Finnigan Trace DSQ mass spectrometer operated at $70 \mathrm{eV}$ with a mass range of $\mathrm{m} / \mathrm{z} 40-800$ and a cycle time of $1.7 \mathrm{~s}$. The gas chromatograph was equipped with a fused silica capillary column as described above for GC. The carrier gas was helium and the same oven temperature program as for GC was used.

\section{Identification and Phylogeny of Genes of the BHP Biosynthetic Pathway}

Biosynthetic genes involved in the BHP pathway were identified in acidobacterial (meta)genomes with PSI-BLAST (Position-Specific iterated BLAST) searches at the protein level (www.ncbi.com) using two iteration steps using in most cases the annotated enzymes from Acidobacterium capsulatum as query sequences. These $A$. capsulatum query sequences were first identified by PSI-BLAST searches of BHP biosynthesis genes annotated in $R$. palustris, Zymomonas mobilis, Burkholderia cenocopacia, M. capsulatus, and Methylobacterium extorquens, species where BHP biosynthetic genes have been assigned (e.g., Perzl et al., 1998; Bradley et al., 2010; Welander et al., 2010, 2012; Neubauer et al., 2015; Schmerk et al., 2015).

Nearly complete $16 \mathrm{~S}$ rRNA gene sequences of the acidobacterial strains and (meta)genomes obtained from environmental samples discussed in the text, were obtained from the ARB SILVA database (https://www.arb-silva.de/) and from the (meta)genomes listed in Table 3, and aligned with ClustalW (Thompson et al., 1994). A phylogenetic tree was generated with MEGA 6 (Tamura et al., 2013) using the Neighbor-joining method (Saitou and Nei, 1987); bootstrapping values were based on 1,000 repetitions and are shown next to the branches (Felsenstein, 1985). The evolutionary distances were computed using the Jukes-Cantor method (Jukes and Cantor, 1969). The analysis involved 72 nucleotide sequences, and a total of 1593 positions in the final dataset. Putative and annotated partial homologs of Shc, HpnC, hpnD, and FdpT proteins were aligned by Muscle (Edgar, 2004) in Mega6 software (Tamura et al., 2013) and edited manually. Phylogenetic reconstruction was performed by maximum likelihood in PhyML v3.0 (Guindon et al., 2010) using the best model according to AIC indicated by ProtTest 2.4 (Abascal et al., 2005) as indicated in the figure legends.

\section{RESULTS}

Thirty-eight Acidobacteria strains distributed over seven subdivisions (SDs 1, 3, 4, 6, 8, 10, and 23) were analyzed for the presence of $\mathrm{C}_{30}$ hopenes and BHPs, and specifically, for the presence of methylated hopanoids. Figure 1 depicts their phylogenetic relationship based on their 16S rRNA gene.

\section{Detection of BHPs in Acidobacterial Cultures}

It has previously been demonstrated that specific membrane lipids of Acidobacteria (i.e., iso diabolic acid and 13,16-dimethyl28-glyceryloxy-octacosanoic acid) can only be released by direct acid hydrolysis of lyophilized cells and not directly by a modified Bligh-Dyer extraction (Sinninghe Damsté et al., 2011, 2014). This was interpreted to indicate that these membrane-spanning lipids that comprised a substantial fraction of the membrane lipids contained large and potentially very polar head groups, making them inaccessible for solvent extraction. Since BHPs often reside in the membrane, where they act as rigidifiers (e.g., Rezanka et al., 2010), we suspected that the classical way of BHP analysis by extraction might miss a substantial fraction of BHPs in Acidobacteria. To test this hypothesis, we modified a commonly applied technique for the analysis of BHP derivatives, i.e., specific oxidation with periodic acid followed by reduction with sodium borohydride to convert complex polyfunctionalized BHPs into easy-to-analyze hopanoid alcohols (Rohmer et al., 1984) and applied this technique to lyophilized cells instead of to the extract of the cells (see experimental). Comparison of the yield of extended (i.e., $\mathrm{C}_{31}$ and $\mathrm{C}_{32}$ ) hopanols from Acidobacteriaceae bacterium A2-4c, belonging to SD1, revealed that direct treatment on lyophilized cells resulted in a substantial increase in yield (i.e., by approximately one order of magnitude; Figure 2). This indicates that, in addition to iso diabolic acid and its derivatives, also BHP derivatives are difficult to extract from acidobacterial cells. Consequently, we analyzed our strains by application of the "Rohmer method" on lyophilized cells.

\section{Extended Hopanols Formed by Rohmer Degradation of Intact Cells}

Cell material of 24 different strains of six subdivisions (SDs 1, $3,4,6,8$, and 10) of the Acidobacteria were subjected to the Rohmer reaction to test the presence of BHPs. $\mathrm{C}_{32}$, and in some cases $\mathrm{C}_{31}$ hopanols, were detected in all strains of SD 1 and 3 but not in SD 4, 6, 8, and 10 (Table 1). An exception was the photosynthetic thermophilic acidobacterium C. thermophilum $\mathrm{B}$, where bishomohopanol was detected, in agreement with the reported occurrence of BHT derivatives in this strain (Costas et al., 2012b). In almost all strains only bishomohopanol was detected; this hopanol is derived from the oxidation of tetrafunctionalized BHPs and subsequent reduction (Rohmer et al., 1984). Five strains (i.e., Acidobacteriaceae bacterium A2-4c, “Ca. Koribacter versatilis Ellin345," Terriglobus roseus $\mathrm{KBS}^{\mathrm{T}}{ }^{\mathrm{T}}$, Paludibaculum fermentans $\mathrm{P} 105^{\mathrm{T}}$, and "Ca. Solibacter usitatus Ellin6076;" Table 1) contained variable relative abundances (up to $45 \%$ ) of homohopanol, derived from pentafunctionalized BHPs. 


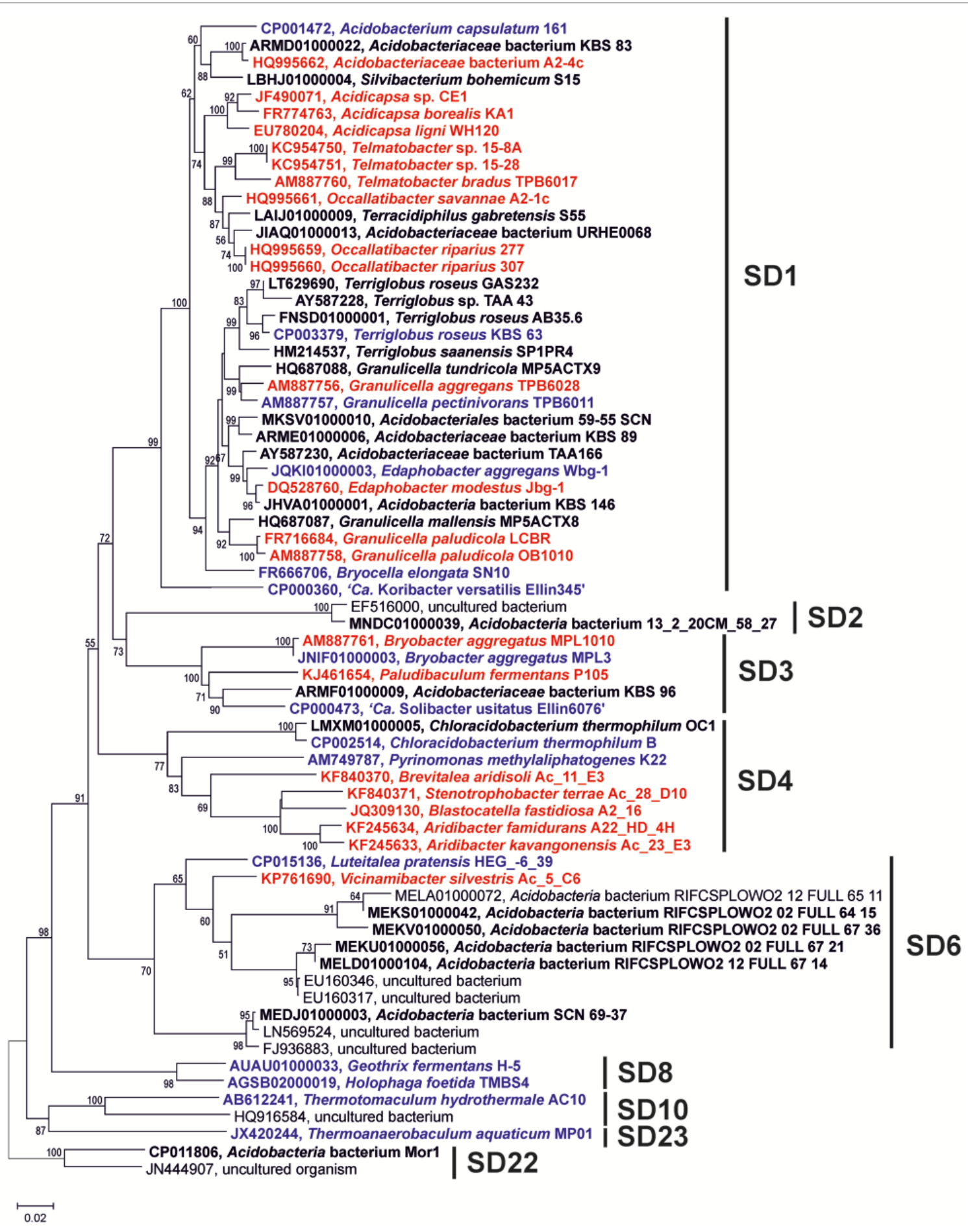

FIGURE 1 | Phylogenetic tree of the nearly complete 16S rRNA gene sequences of the Acidobacteria discussed in the text. The percentage of replicate trees in which the associated taxa clustered together in the bootstrap test (1,000 replicates) are shown next to the branches. Scale bar indicates $2 \%$ sequence divergence. Names in red bold indicate strains in which presence of BHP has been assessed in cultures; names in black bold indicate strains in which the genome has been screened for the presence of the genes discussed in the text, names in blue bold indicate strains in which both the BHP and genome screening has been performed. 


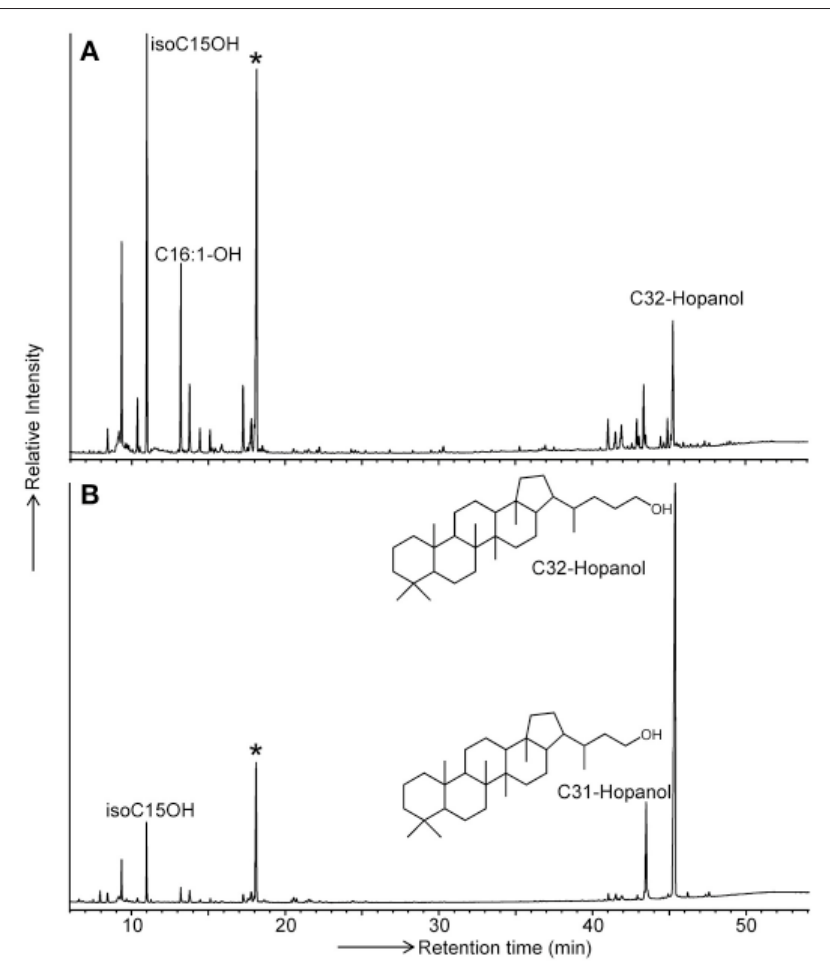

FIGURE 2 | GC traces of the products formed by the Rohmer treatment of (A) the total extract and (B) total cell material of Acidobacteriaceae bacterium A2-4c. Released hopanoids are present in the form of hopanols (analyzed as their TMS derivatives). Bacteriohopanetetrol derivatives are transformed by the Rohmer treatment into the $\mathrm{C}_{32}$ hopanol, bacteriohopanepentol derivatives are transformed into the $\mathrm{C}_{31}$ hopanol. The star indicates the internal standard added prior to analysis in a fixed concentration. Since the peak areas of the hopanols relative to the internal standard in $\mathbf{( B )}$ is much larger, the hopanol yield is much higher when the Rohmer reaction is applied to total biomass.

Methylated extended hopanols (derived from 2-methyl or 3-methyl BHPs) were only detected in one (out of three) batch cultures of "Ca. Koribacter versatilis Ellin345." In this case, an extended hopanol was tentatively identified as 2,3-dimethyl-bishomohopanol on the basis of its mass spectral features (Figure 3) and relative retention time. It comprised ca. $9 \%$ of the hopanols released by the Rohmer degradation.

\section{$\mathrm{C}_{30}$ Hopanoids in Acidobacteria}

All 24 strains analyzed for the presence of BHPs and 14 others were also examined for the presence of the $\mathrm{C}_{30}$ hopanoids. The occurrence of hop-17(21)-ene is reported in Table 1. This hopanoid is formed from both diploptene [hop-27(29)-ene] and diplopterol upon acid hydrolysis, the extraction method that was typically applied (Sinninghe Damsté et al., 2011, 2014). If cells were extracted with a modified Bligh-Dyer protocol, these two latter hopanoids (mostly diploptene) were detected instead of hop-17(21)-ene. In general, strains that do produce BHPs also contain $\mathrm{C}_{30}$ hopanoids although there are some exceptions (Table 1). $\mathrm{C}_{30}$ hopanoids were not detected in strains that do not produce BHPs (Table 1). The $\mathrm{C}_{30}$ hopanoid data reveal that hopanoid synthesis occurs in all strains of the SD1 Acidobacteria analyzed.

\section{BHP Biosynthetic Genes in Genomes of Cultured Acidobacteria}

To be able to compare the in situ production of BHPs with the biosynthetic potential at the genetic level, we screened available complete genomes of cultivated acidobacteria for biosynthetic genes involved in BHP production (see Figure 4 for the biosynthetic scheme). Thirty-one genomes from SDs $1,3,4,6,8,10$, and 23 were examined using protein BLAST searches. The results are listed in Table 2 . In all acidobacteria investigated (almost) all genes encoding the MEP pathway of isoprenoid biosynthesis ( $d x s, d x r$, ispD, ispE, ispF, isp G, ispH; Zhao et al., 2013) were detected. An exception is the $d x s$ gene that was lacking in six species (Table 2). In Escherichia coli it has been demonstrated that a point mutation of the gene encoding the E1 subunit of the pyruvate dehydrogenase complex (aceE) can overcome the lack of $d x s$ (Sauret-Güeto et al., 2006). In all of the acidobacterial species lacking $d x s$, aceE was detected instead. All examined acidobacterial genomes also encoded isp $A$, the gene encoding farnesyl diphosphate synthase. Therefore, all of the examined acidobacterial genomes have the genetic capacity to produce the isoprenoid $\mathrm{C}_{15}$ building block used in various biosynthetic pathways, including BHP synthesis (Figure 4).

The next step in the production of BHPs is the coupling of two molecules of farnesyl diphosphate and production of squalene. Recent evidence has revealed that in most bacteria this proceeds via a three-step mechanism (Figure 4) catalyzed by three different enzymes encoded by $h p n D, h p n C$, and $h p n E$ (Pan et al., 2015). None of these genes were detected in Acidobacteria of SD8, SD10, and SD23 neither in Pyrinomonas methylaliphatogenes $\mathrm{K} 22^{\mathrm{T}}$ belonging to SD4 (Table 2), whereas all three genes were generally detected in the genomes of SD1 and SD3 species and in C. thermophilum B and OC1 (SD4) and in Luteitalea pratensis HEG_-6_39 (SD6) (Table 2). The genomes of all SD1 and SD3 species and C. thermophilum B and $\mathrm{OC} 1$ contained $s h c$, encoding the enzyme responsible for the cyclization of squalene to form the hopanoid building block diploptene (Table 2; Figure 4). In C. thermophilum B and OC1 the detected shc genes are only remotely related to those of other Acidobacteria and much more closely affiliated with shc genes of Cyanobacteria (Figure 5). Two species (G. pectinivorans DSM 21001 and "Ca. S. usitatus Ellin 6076") contained two copies of $s h c$ in their genome. In the shc phylogeny (Figure 5) both copies fall in the SD3 cluster. No shc gene could not be annotated in the remaining species (SDs 6, 8, 10, 23, and P. methylaliphatogenes K22; Table 2). In four SD1 genomes (i.e., those of Silvibacterium bohemicum S15, Acidobacteriaceae bacterium KBS 89, Granulicella mallensis MP5ACTX8 $8^{\mathrm{T}}$, and Acidobacteriaceae bacterium TAA166) in which shc could be annotated, not all of the three genes involved in squalene synthesis ( $h p n D, h p n C$, and $h p n E)$ were present (Table 2). However, in those genomes, we detected a gene annotated as a farnesyl diphosphate farnesyl transferase, which may be coding an alternative enzyme involved in squalene synthesis. This protein is highly homologous to proteins encoded by 


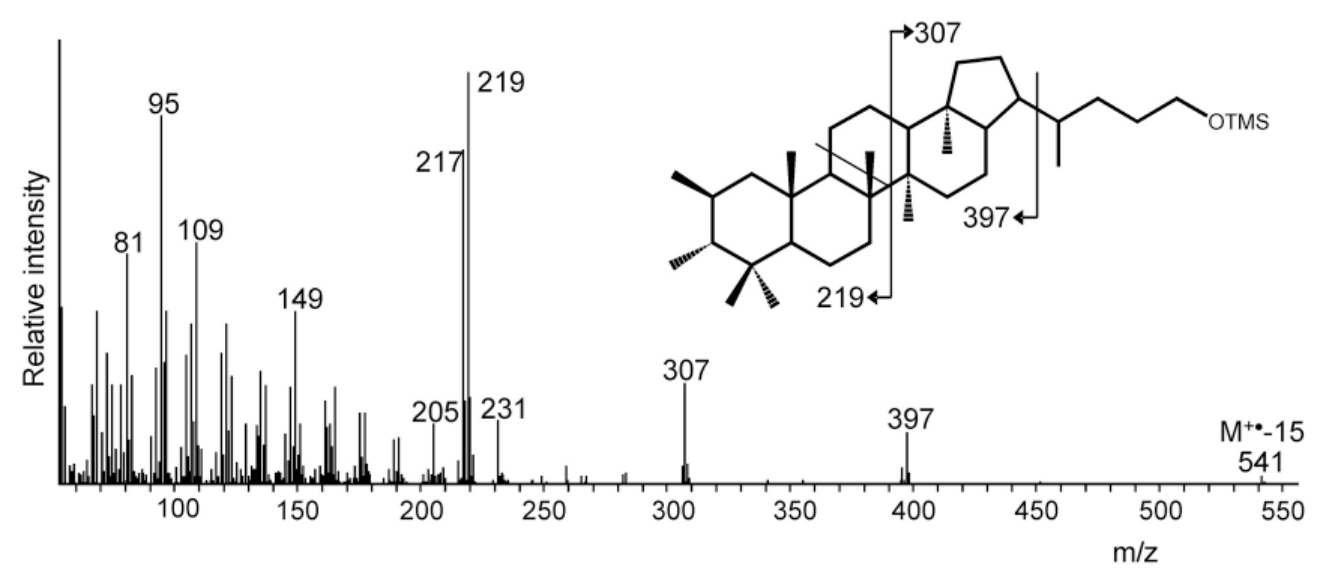

FIGURE 3 | Mass spectrum of a putative dimethylated bishomohopanol (as TMS derivative) formed by Rohmer degradation of total cell material of "Ca. Koribacter versatilis" Ellin345. The methylation at position C-2 and C-3 is unprecedented but supported by the indicated mass spectral fragmentation and the presence of both the hpnP and hpnR genes in the genome of "Ca. K. versatilis Ellin345" (Table 2). The indicated stereochemistry of the additional methyl groups is hypothetical.

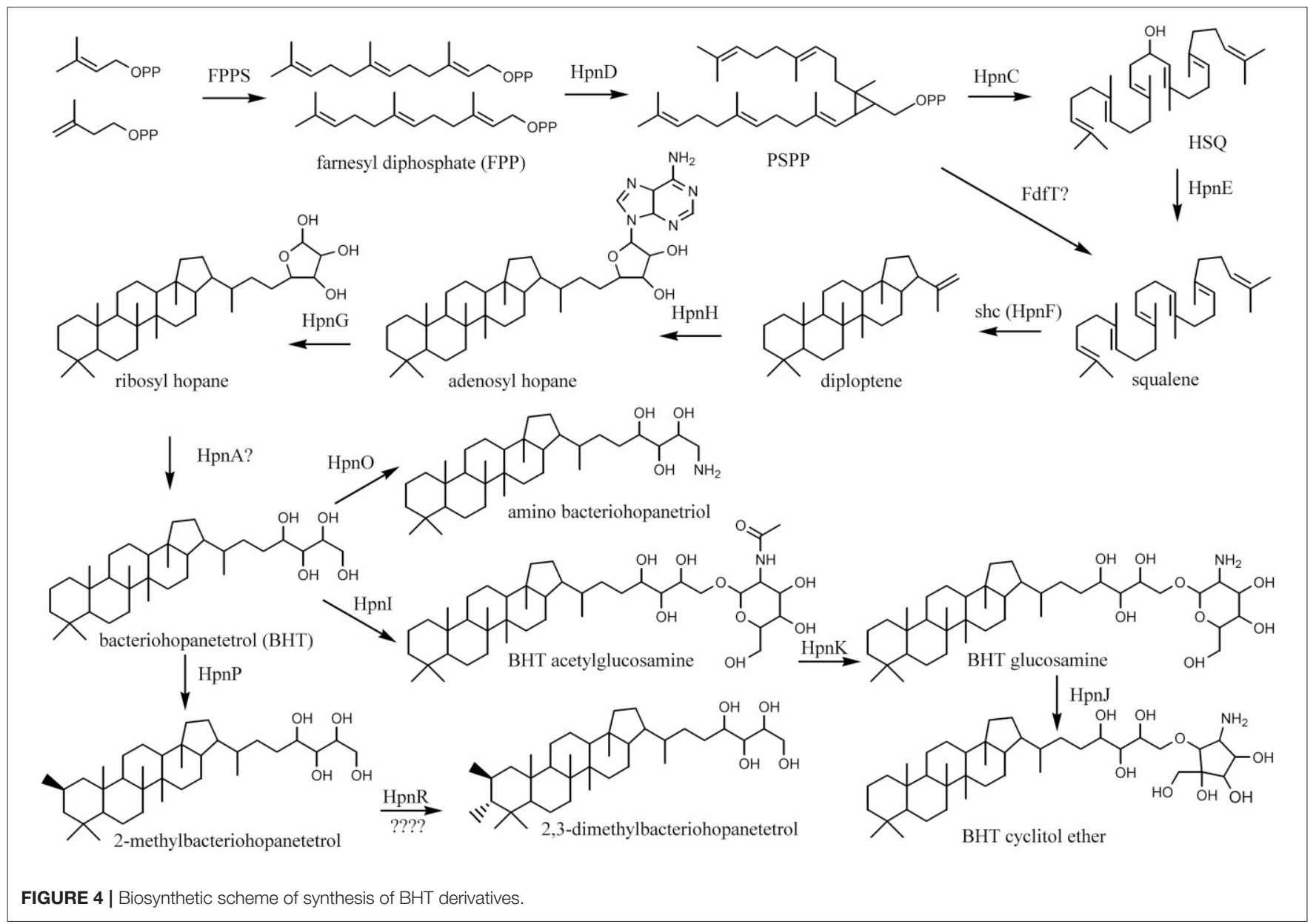

genes also annotated as farnesyl diphosphate farnesyl transferases present in the genomes of Parabulkholderia species, belonging to the Betaproteobacteria (Figure 6). In the two strains of C. thermophilum an additional gene copy of $h p n D$ was also identified; it is phylogenetically most closely related to species of green sulfur bacteria (Figure 6).

All but one of the species harboring the shc gene also encode the two known genes involved in the conversion of diploptene 


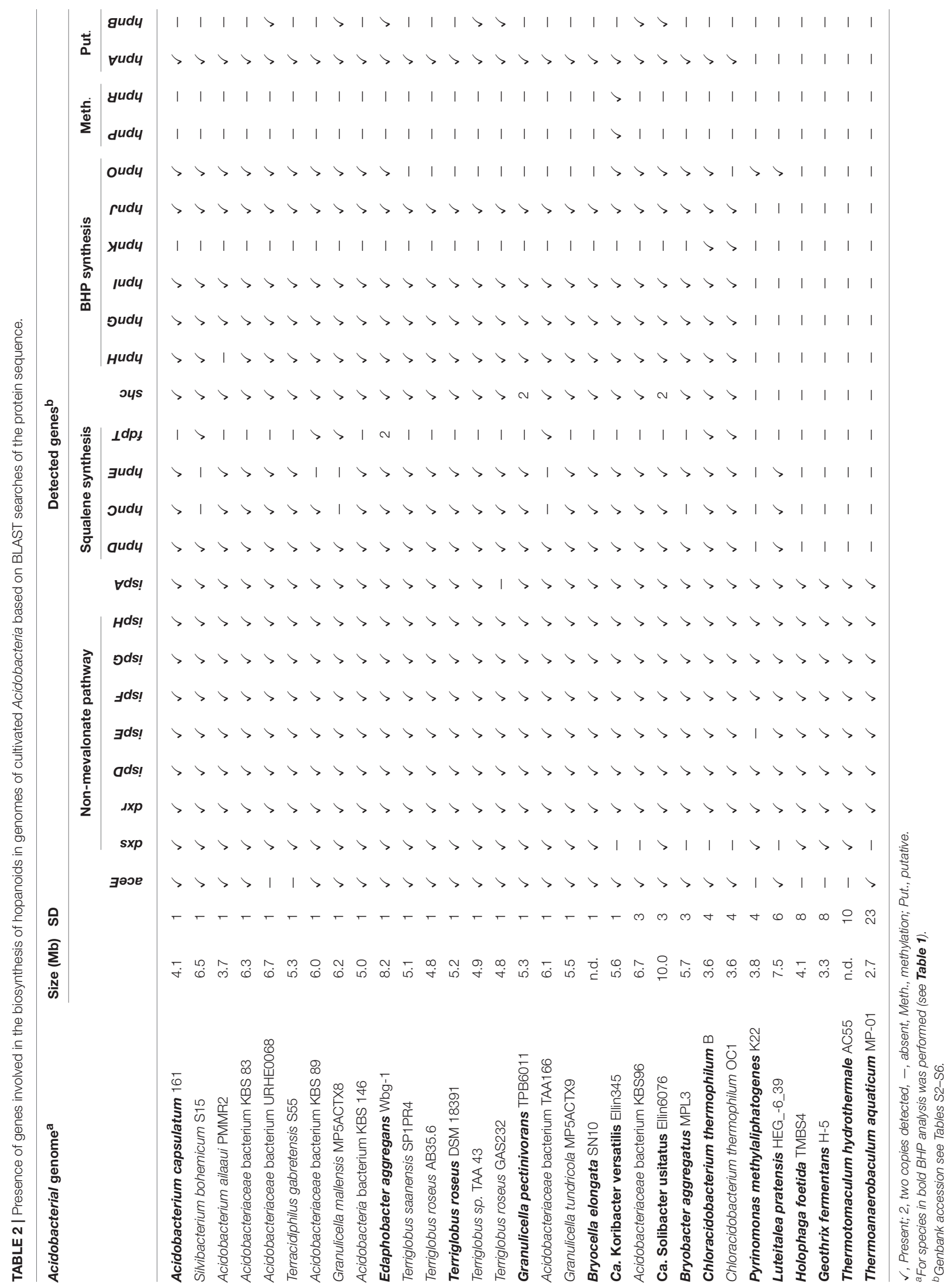




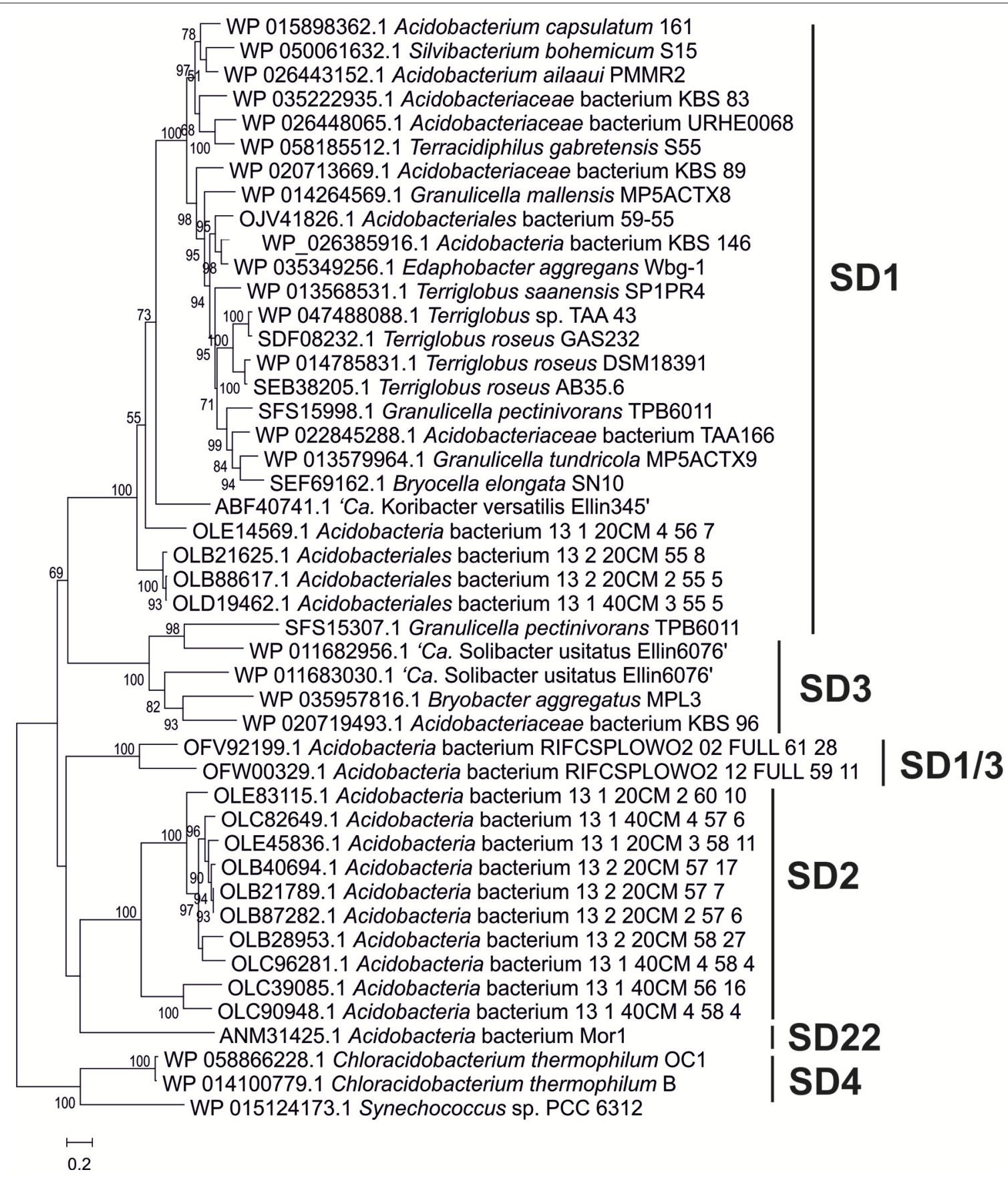

FIGURE 5 | Phylogenetic tree of the Shc proteins in the acidobacterial genomes of cultures and environmental genomes. This tree was constructed using the maximum likelihood method with a LG model plus gamma distribution and invariant sites ( $L G+G+I)$. The analysis included 750 positions in the final dataset. The scale bar represents number of amino acid substitutions per site. Branch support was calculated with the approximate likelihood ratio test (aLRT) and values $\geq 50 \%$ are indicated on the branches. In general, it reveals the phylogeny that is also apparent from the 16S rRNA gene tree (Figure 1) with distinct clusters for the SD1, SD2, SD3, and SD22 clusters. The only Shc proteins encountered in Acidobacteria SD4 (i.e., in C. thermophilum B and OC1) differ substantially from those of other Acidobacteria and are more closely related to Shc proteins encountered in Cyanobacteria (e.g., Synechoccus sp.). The second Shc protein of the SD1 acidobacterium G. pectinivorans DSM21001 falls in SD3 and is most closely related to the second copy of Shc of "Ca. S. usitatus Ellin 6076."

to BHT (i.e., $h p n H$ and $h p n G$ ). We suspect that $h p n A$, a sugar epimerase, is also involved in this conversion but there is no published experimental evidence for that (Table S1). The $h p n B$ gene, for which experimental evidence is also lacking that it is involved in the BHP biosynthetic pathway, is present in only a limited number of the examined genomes, suggesting that it is not essential for BHP synthesis. This is in contrast to the hpnA gene, which is present in all acidobacteria possessing the genes 

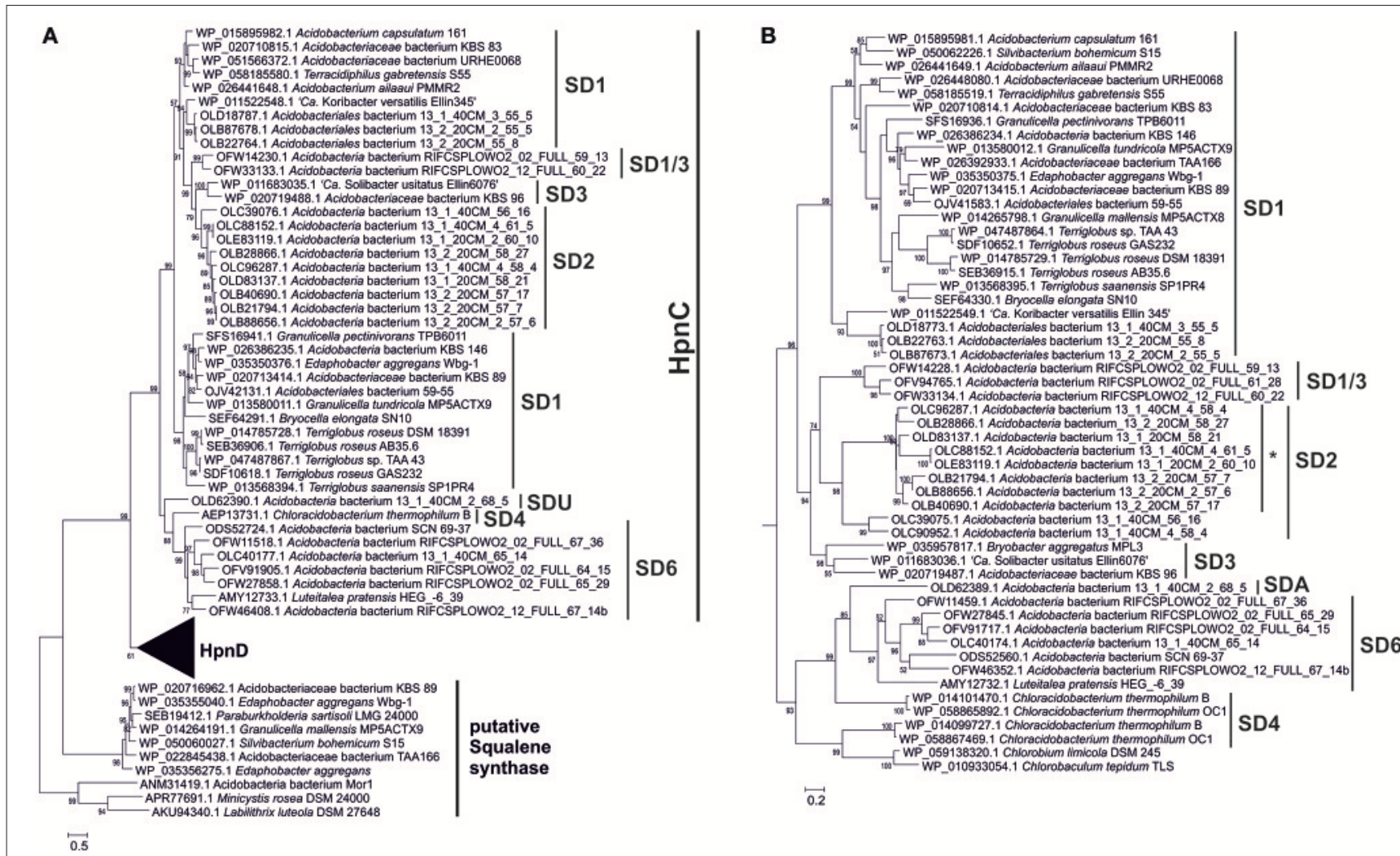

FIGURE 6 | Phylogenetic tree of the HpnC, HpnD, and FdfT proteins in the acidobacterial genomes of cultures and environmental genomes. The tree was constructed using the maximum likelihood method with a LG model plus gamma distribution and invariant sites $(L G+G+I)$. The analysis included 509 positions in the final dataset. The scale bar represents the number of amino acid substitutions per site. Branch support was calculated with the approximate likelihood ratio test (aLRT) and values $\geq 50 \%$ are indicated on the branches. The first part (A) of the tree shows the phylogeny of the HpnC and FdfT proteins; zoom in (B) showing the phylogeny of the HpnD proteins. The HpnC tree generally reveals the phylogeny that is also apparent from the $16 \mathrm{~S}$ rRNA gene tree (Figure 1) with distinct clusters for the SD1, SD2, SD3, SD4, SD6, and SD1/3 acidobacteria. Five species of SD1 acidobacteria also contained an FdtT protein, which is only remotely related to the $\mathrm{HpnC}$ and HpnD proteins. These FdtT proteins are closely related to the FdtT proteins of Betaproteobacteria (e.g., Parabulkholderia sartisoli). The HpnC tree generally also reveals the phylogeny that is also apparent from the 16S rRNA gene tree (Figure 1) with distinct clusters for the SD1, SD2, SD3, and SD1/3 acidobacteria. The sequences in the SD2 cluster annotated with an asterisk are annotated as HpnC but in fact represent a fused protein HpnCD (see text and Figure 7). HpnC was considered until the amino acid position 279-339 up to the amino acids RAG/RTG/RVG, while the rest of the protein was cropped and used as a new entry in the alignment and phylogenetic tree. As observed in the Shc protein tree (this figure) the HpnD protein of the SD4 acidobacterium C. thermophilum is only distantly related to the HpnD protein of other acidobacteria. The closest relatives are HpnD proteins of green sulfur bacteria (e.g., Chlorobium limicola and Chlorobaculum tepidum).

required for BHT synthesis. In most SD1 Acidobacteria hpnA is also organized in a specific gene cluster together with $h p n G$ (see below), which provides complementary circumstantial evidence for its potential role in BHP synthesis.

Only the genome of $C$. thermophilum $\mathrm{B}$ encodes all the genes (Table 2) required for the conversion of BHT into the composite BHP, BHT cyclitol ether (Figure 4). Other genomes contain some but not all of these genes (Table 2). The gene that is responsible for the last step of the conversion of BHT into amino bacteriohopanetriol (Figure 4), occurs in many of the examined strains but not all (Table 2). This gene was also detected in some acidobacteria that do not possess the shc gene. It is likely that this is caused by their close relatedness with other aminotransferases (e.g., argD; Welander et al., 2012).

Of special interest were the genes encoding enzymes responsible for methylation of the A-ring of BHPs. Welander et al. (2010) and Welander and Summons (2012) previously reported the presence of $h p n P$ and $h p n R$ in the genome of the acidobacterium " $\mathrm{Ca}$. K. versatilis Ellin345," which was confirmed by our BLAST searches (Table 2; hpnP WP_011523124.1 and $h p n R$ WP_011523840.1; both with sequence identity of ca. $60 \%$ with the genes of $R$. palustris TIE-1 (Welander et al., 2010) and M. capsulatus (Welander and Summons, 2012), respectively). However, these genes were absent in all of the other examined acidobacterial genomes (Table 2).

The phylogeny of the detected BHP biosynthetic genes (e.g., Figures 5, 6) generally showed a similar clustering as that observed for the 16S rRNA gene phylogeny (Figure 1). The location of the BHP biosynthetic genes in the Acidobacteria genomes investigated showed some distinct gene clustering organization. Three clusters were identified (Figure 7). Cluster A is composed of $h p n C, h p n D$, and $h p n E$, preceded by a gene with an unknown function (ug2). Cluster B is composed of ispA, shc, and $h p n H$, followed by a gene with an unknown function (ug3). 
Lastly, cluster $\mathrm{C}$ is composed of $h p n A$, and $h p n G$, followed by another gene with an unknown function (ug1). In some cases these gene clusters have been expanded by the insertion of other genes or have lost genes (indicated by stippled lines in Figure 7). In Terracidophilus gabretensis $\mathrm{S} 55^{\mathrm{T}}$ these three clusters occur in one large concatenated cluster, including $h p n J$ (Figure 5). In other SD1 acidobacteria, this ordering is seen to an increasingly less extent. For example, in Acidobacteriaceae sp. KBS83 the ordering is almost the same as in T. gabretensis $\mathrm{S} 55^{\mathrm{T}}$ except that there is an insertion of two additional genes between clusters A-C and $h p n J$ (Figure 7). On the other side of the spectrum, there are SD1 acidobacteria that lack one or two of the gene clusters, either because they miss one or more of the genes of a gene cluster (e.g., $h p n C$ and/or $h p n E$ in cluster A) or because the cluster was split into two parts (e.g., gene cluster B in " $\mathrm{Ca}$. Koribacter versatilis Ellin345"). In SD3 and the one species of SD4 that possesses genes for BHP synthesis (C. thermophilum B and OC1), the ordering of genes as observed for SD1 acidobacteria is much less apparent. Only gene cluster C could be recognized in SD3 acidobacteria (Figure 7). The localization of the other genes that occur predominantly clustered in SD1 was found to be more scattered.

\section{Identification of Genes Involved in BHP Biosynthesis in Acidobacterial Genomes from the Environment}

Recently, a number of environmental genomes of acidobacteria obtained from environmental metagenomic datasets (e.g., soil, groundwater, wastewater sludge) has become publically available (e.g., Anantharaman et al., 2016; Butterfield et al., 2016; Speth et al., 2016). Some of these genomes are from acidobacteria that phylogenetically do not fall in phyla for which cultivated members are known and allow to search for the more widespread occurrence of BHP synthesis in Acidobacteria. Accordingly, we examined the presence of genes involved in BHP biosynthesis in 42 acidobacterial environmental genomes (Table 3). A complication with this analysis is that these environmental genomes are typically not complete and, thus, the absence of a gene should be taken with caution. The genomes are classified as indicated in Table 3 based on 16S rRNA gene when available (Figure 1) and on the phylogenetic clustering of the other genes studied (e.g., Figures 5, 6). Four of them fall in SD1 (with three of the most closely related to " $\mathrm{Ca}$. K. versatilis Ellin345"), 11 in SD2, 3 in SD4, 10 in SD6; SD22, and SD23 are each represented by one genome. The other genomes can't clearly be assigned to a SD since they lack $16 \mathrm{~S}$ rRNA gene (or contain only a small part of it) and fall in phylogenomic clusters with no cultured relatives. Five genomes cluster in a group that is phylogenetically (based on the genes of the BHP pathway) closely related to SD1 and SD3 (labeled 1/3 in Table 3). A group of two genomes belong to a cluster closely related to SD3 and SD4 (labeled 3/4), and there are four genomes that cannot be classified in this way and are labeled $\mathrm{U}$ in Table 3.

The genes of the MEP pathway were (partially) identified in all the analyzed genomes considered here except for the genome classified within SD22 (Table 3). This genome, however, contained most genes of the mevalonate pathway for DMAPP biosynthesis (Zhao et al., 2013; Figure 7). All but one examined acidobacterial genomes also encoded ispA, the gene encoding farnesyl diphosphate synthase. Genes encoding enzymes involved in squalene synthesis from farnesyl diphosphate were only detected in genomes of SD1, SD2, SD6, and the SD1/3 cluster. In most of the genomes of SD2, the $h p n C$ and $h p n D$ are fused into one gene with approximately twice the size of the individual $h p n C$ and $h p n D$ genes. This occurs more often with genes that are of the same functional category (e.g., Yanai et al., 2001). Although the organization of the $h p n C-h p n D-h p n E$ cluster is most common in bacteria (Pan et al., 2015), a BLAST search indicated that a fused $h p n C D$ gene also occurs in other bacterial species; this SD2 gene is most closely related to the $h p n C D$ gene in specific Actinobacteria (e.g., Actinopolyspora species, Blastococcus saxobsidens) and Alphaproteobacteria (e.g., Rhodospirillum centenum).

Shc and some other crucial genes for the biosynthesis of BHP ( $h p n H, h p n G$, potentially $h p n A)$ and its derivatives ( $h p n I, h p n J, h p n O)$ were only identified in the environmental genomes of the SD1, SD2, and SD1/3 group (Table 3 ). The SD22 genome contains shc and $h p n H$ but it lacks the genes for squalene synthesis from farnesyl diphosphate commonly encountered in Acidobacteria. However, a gene was identified that shows homology with genes annotated as squalene synthase in other bacterial groups. This tentatively suggests that the SD22 Acidobacterium is capable of BHP biosynthesis, albeit in a rather different way than all other acidobacteria examined. No genes involved in the methylation of BHPs were identified in the acidobacterial genomes obtained from the environmental genomes, including those that are phylogenetically closely related to "Ca. K. versatilis Ellin345." Consequently, it seems likely that only acidobacteria falling in the cluster phylogenetically related to SD1, SD2 and SD3, and SD22 are potentially capable of BHP synthesis.

The genomic organization of the genes involved in BHP synthesis in the apparently most complete environmental genomes (i.e., based on the presence of an (almost) complete set of genes for BHP biosynthesis) is shown in Figure 7. The $\mathrm{SD} 1$ genomes, which are most closely related to " $\mathrm{Ca}$. K. versatilis Ellin345," show an organization that is comparable to most other $\mathrm{SD} 1$ acidobacteria. In the species of SD2 gene, cluster A is always encountered, albeit that the genes $h p n C$ and $h p n D$ are in most cases fused (Figure 7). Gene cluster $C$ is in all cases the same but gene cluster $\mathrm{B}$ occurs in a fragmented form. SD3 and SD $1 / 3$ acidobacteria contain gene cluster $C$ but clusters $A$ and $B$ are reduced by the absence of $u g 2$ and $u g 3$, respectively, which are commonly associated with these clusters in SD1 genomes. In C. thermophilum (SD4) and the environmental genome Mor1 (SD22) the organization of the BHP genes as observed in SD1 Acidobacteria is no longer evident.

\section{DISCUSSION}

\section{Relation of Pheno- with Genotype with Respect to BHP Production}

In this study, we compare BHP and $\mathrm{C}_{30}$ hopene production with the biosynthetic capacity at the gene level for hopanoid production. Although 38 acidobacterial strains were analyzed 


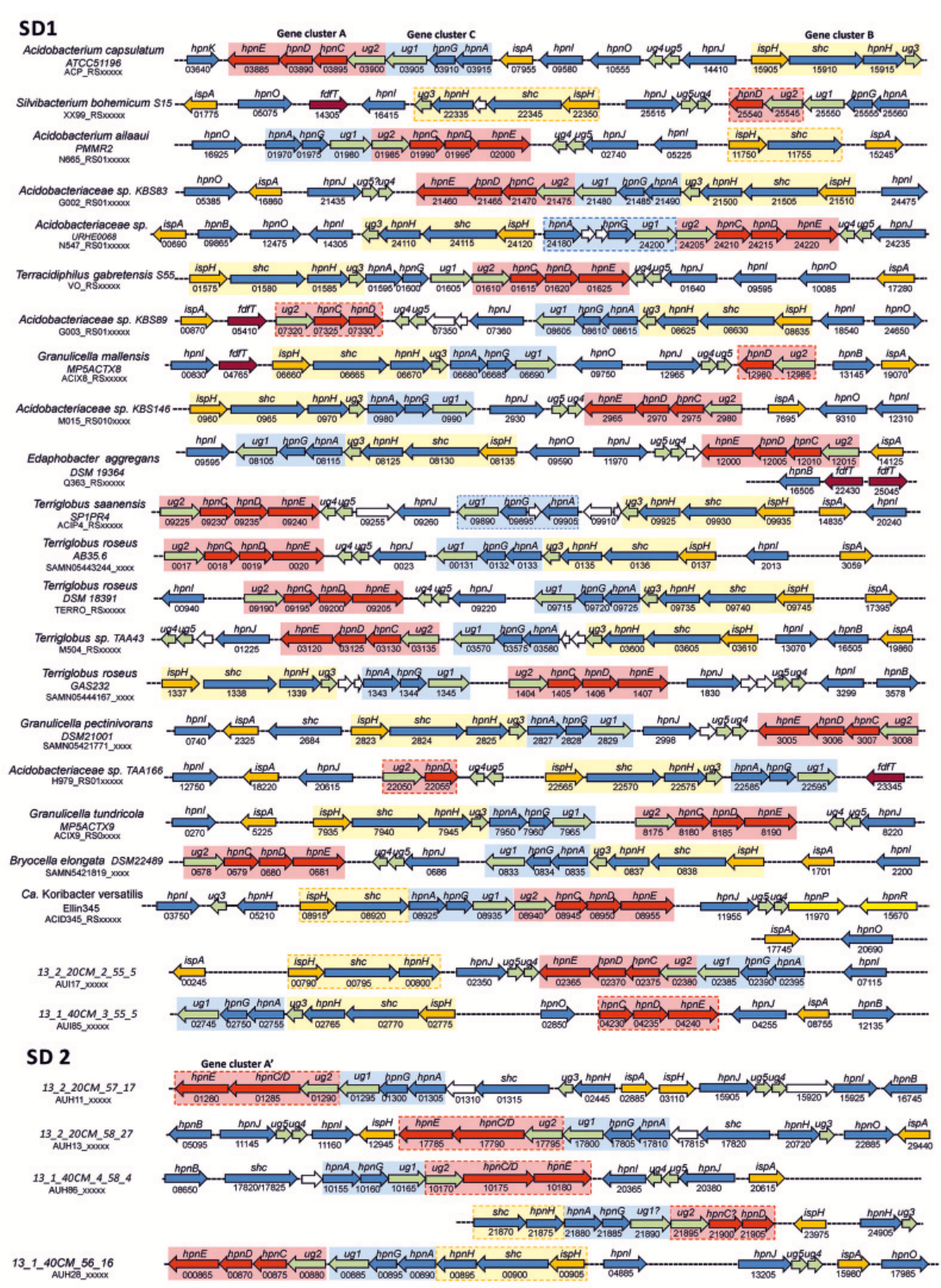

SD $1 / 3$

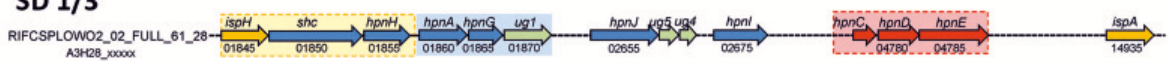

SD3

Acidobacteriaceaes sp. KBS96

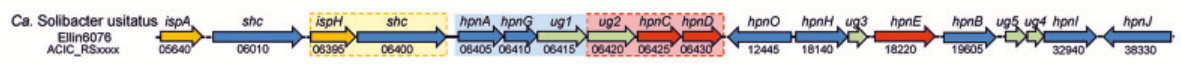
Bryobacter aggregatus MPL3

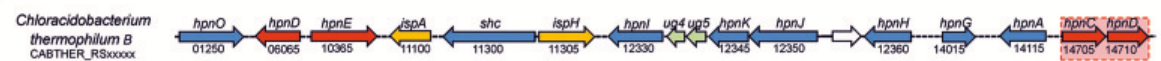

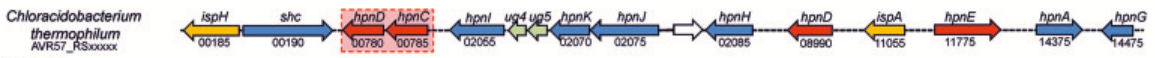

SD 22

Mar1

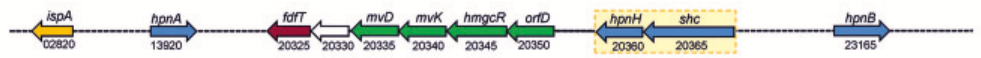

FIGURE 7 | (Continued) 


\section{FIGURE 7 | Continued}

Location of BHP biosynthetic genes and gene clusters in the genomes of SD1, SD3, and SD4 Acidobacteria and a number of selected environmental genomes as determined by BLAST protein searches. Species were ordered as indicated by the phylogeny of the shc gene. Stippled lines indicate a distance between the genes. The numbers refer, in combination with the code below the species name, to the locus tag in the annotated genome from the NCBI database. These numbers typically increase by 5 for every next gene. Color codes of genes are: orange, genes involved in the biosynthesis of farnesyl diphosphate; red and dark red (putative), genes involved in the biosynthesis of squalene; blue, genes involved in BHP biosynthesis; yellow, genes involved in the methylation of BHPs; dark green, genes involved in the mevalonate pathway of isoprenoid biosynthesis, light green, genes often of unknown function associated with identified gene clusters. Names of genes refer to Table S1. Three gene clusters were often encountered and these are indicated in different background colors (red, blue, and yellow). When these cluster are indicated with a stippled box, these clusters have been slightly modified by the insertion or deletion of one or a few genes. ${ }^{*}$ There is only a nucleotide sequence corresponding to the open reading frame of $h p n C$ of C. thermophilum B (WP_014101470.1) between amino acids 38-227.

for the presence of $\mathrm{BPH}$ production in culture and the 31 acidobacterial genomes were screened for the BHP biosynthetic pathway genes, this comparison is somewhat complicated by the fact that only for 15 strains both hopanoid production and genome data are available at the same time (Table 2; species in bold). However, the $16 \mathrm{~S}$ rRNA gene phylogenetic tree shows that, in most cases, for strains that only have genome data available we have analyzed the BHP production in phylogenetically closely related strains (Figure 1).

The general picture that emerges from this comparison is that there is an excellent match in pheno- and genotype in terms of hopanoid production. All analyzed SD1 and SD3 acidobacterial strains have the genetic capacity for hopanoid production and do produce hopanoids. There are two out of 21 tested SD1 acidobacteria (Terriglobus sp. KMR, and Telmatobacter bradus TPB $6017^{\mathrm{T}}$; Table 1) that did not produce $\mathrm{C}_{30}$ hopenes. However, in these cases the production of BHPs was not determined. Examination of other strains showed that even when hop-17(21)ene is absent, BHPs may still be produced (Table 1), indicating that the absence of hop-17(21)-ene cannot be interpreted to indicate the absence of hopanoid production. Furthermore, in both cases where hop-17(21)-ene was lacking, positive evidence for hopanoid production was obtained for phylogenetically

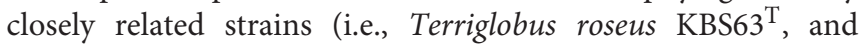
Telmatobacter sp. 15-8A and 15-28; Table 1).

Also for SD4 acidobacteria a good match between phenoand genotype was observed. Only C. thermophilum harbored the genes for hopanoid production (Table 2) and also did produce them (Table 1). The other SD4 acidobacteria did not produce hopanoids nor did possess the biosynthetic genes. It should be noted that $C$. thermophilum is quite distinct from other SD4 acidobacteria with respect to the $16 \mathrm{~S}$ rRNA gene phylogeny (Figure 1), physiology (i.e., the only photoheterotroph in the phylum Acidobacteria; Bryant et al., 2007), and membrane lipid composition (Sinninghe Damsté et al., 2014), and this is confirmed here by its unique capacity of producing hopanoids as the only SD4 acidobacterium so far. In a study of the genome of C. thermophilum B, Costas et al. (2012a) already pointed out that this species is rather distinct from other Acidobacteria; in $<20 \%$ the closest relative of a gene was a gene of another acidobacterium (i.e., A. capsulatum, "Ca. K. versatilis Ellin345," and "Ca. S. usitatus Ellin 6076"), whereas this was the case for slightly over $50 \%$ for other Acidobacteria. This is also evident from our data: both the shc gene (Figure 5) and the second copy of the $h p n D$ gene (Figure 6) are most closely related to other groups of bacteria. This once more illustrates the unique position of $C$. thermophilum within the Acidobacteria.

All other examined acidobacteria from other subdivisions (i.e., SD6, SD8, SD10, and SD23) did not produce hopanoids

(Table 1) and also did not possess the genetic capacity to do so (Table 2). So this dataset allows concluding that (i) there is a clear dichotomy within the phylum Acidobacteria with respect to hopanoid production, and (ii) that when acidobacterial strains possess the genes to produce hopanoids, they express them, at least under the (highly variable) culture conditions that were used to grow them.

This conclusion is supported by the occurrence of genes involved in BHP biosynthesis in environmental acidobacterial genomes belonging to SD1 (Table 3). This survey, however, also suggested that BHP biosynthesis may also occur in some other SDs. The environmental genomes of SD2 (which has no cultured relatives) derived from soil (Butterfield et al., 2016) appeared to have the genetic potential to produce BHPs. This also holds true for a group of acidobacteria occurring in low-oxygen groundwater (Anantharaman et al., 2016), phylogenetically related to SD1 and SD3 acidobacteria. Lastly, the environmental genome of an SD22 acidobacterium associated with the cyanobacterium Moorea producens also shows distinct sign of the capability to produce BHPs, albeit in a completely different way than the other acidobacteria. Genomes of SD6 acidobacteria obtained from environmental metagenomes are genetically capable of producing squalene but do not possess shc and other BHP-related genes (Table 3), as observed for the SD6 acidobacteria available in pure culture (Table 2). The other genomes of acidobacteria obtained from metagenomes analyzed here do not show any signs of the genetic capacity to biosynthesize BHPs, in good agreement with the genomic data of acidobacteria available in culture (Table 2). This also confirms that C. thermophilum B and OC1 are an exception in SD4.

\section{Squalene Biosynthesis: A Potential Shortcut Inherited from Betaproteobacteria?}

Pan et al. (2015) recently established that the production of squalene, an important intermediate in the production of hopanoids, in most bacteria proceeds through a threestep mechanism (Figure 4): HpnD catalyzes the formation of presqualene diphosphate (PSPP) from two molecules of farnesyl diphosphate (FPP), HpnC converts PSPP to hydroxysqualene (HSQ), and HpnE, a member of the amine oxidoreductase family, reduces HSQ to squalene. This was rigorously established by 


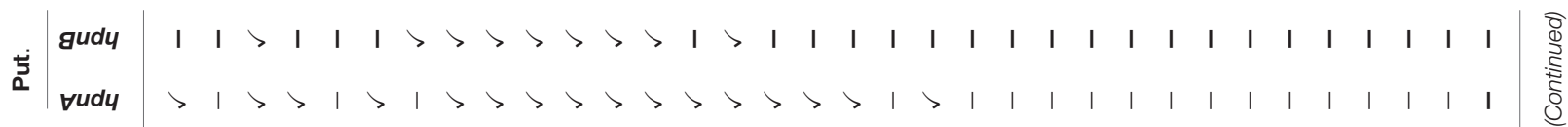

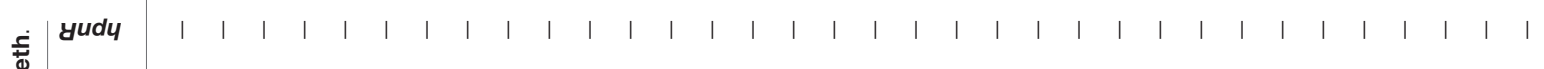

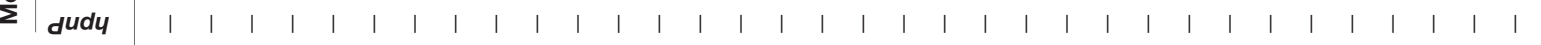

oudy

rudy

$\frac{n}{5}$

究

옴

Iudy

gudy

Hudy

ous

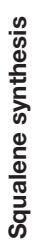

$\perp d p \perp$

эudy

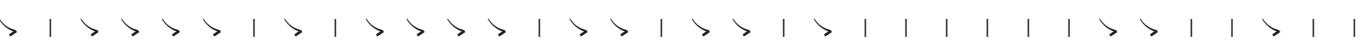

oudy

$>1>$

(

audy

$\forall d s !$

$>$

Hds!

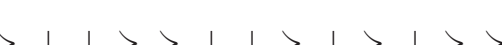

|c.

ods

$y^{d} d$

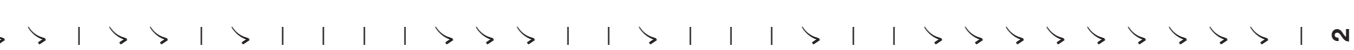

$\exists d s !$

$a d s$

$>N$

1 >

I 1

$>1$

$>$

$>$

$>1$ 


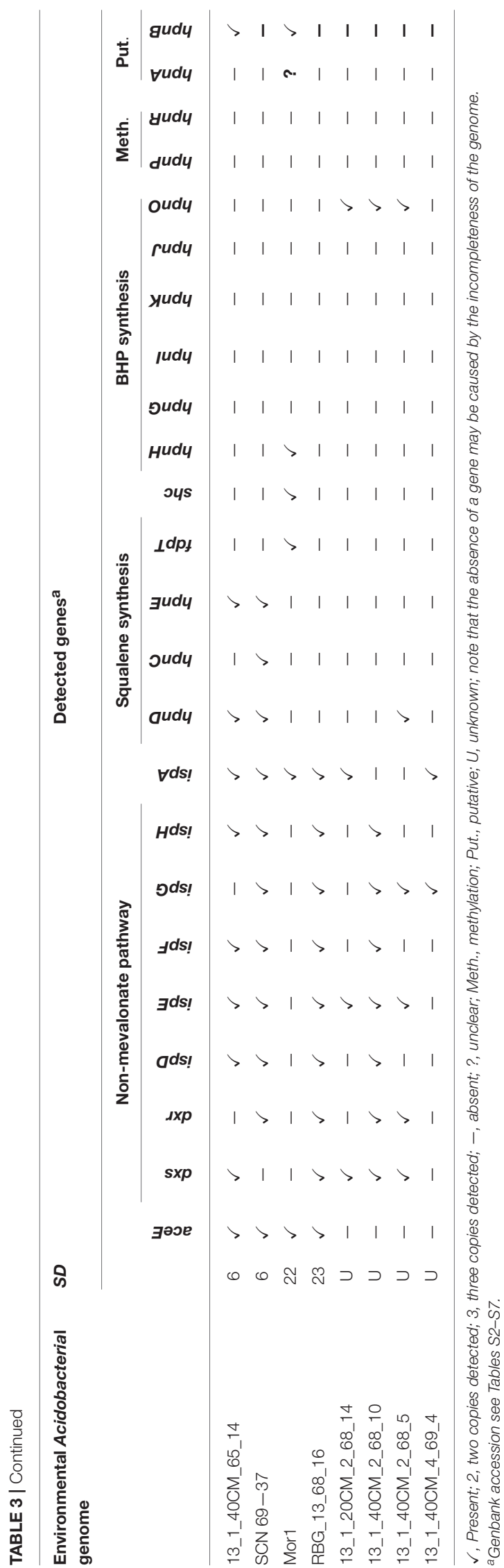

cloning and expressing the $h p n C, h p n D$, and $h p n E$ genes from the hopanoid-producing bacteria $Z$. mobilis and $R$. palustris into Escherichia coli, a bacterium that does not contain genes homologous to $h p n C, h p n D$, and $h p n E$, and their functions were established in vitro and in vivo. These three genes occur typically concatenated in a cluster often directly followed by $\operatorname{shc}(h p n F)$, forming a four-gene cluster in the genome (Perzl et al., 1998).

Most of the hopanoid-producing cultivated acidobacteria possess $h p n C, h p n D$, and $h p n E$, commonly but not always (i.e., in 12 of 21 genomes) organized in a gene cluster (red box in Figure 7). However, this gene cluster is not directly located upstream of $s h c$, as is commonly found in other bacteria (e.g., Perzl et al., 1998), but $h p n C$ is often preceded by a gene with an unknown function (ug2), often annotated as coding for a $\mathrm{Zn}$ binding alcohol dehydrogenase composed of ca. 350 amino acids. This gene is present in all SD1 and SD3 acidobacteria but not in C. thermophilum, suggesting that it is not essential for squalene biosynthesis but somehow is associated with $h p n C, h p n D$, and $h p n E$. The dispersal of the $h p n C, h p n D$, and $h p n E$ genes in some other acidobacteria genomes (e.g., Bryobacter aggregatus $\mathrm{MPL}^{\mathrm{T}}$; Figure 7) indicates that organization of these genes in a gene cluster is also not essential for squalene production.

Interestingly, four cultivated acidobacterial species do not possess all three genes commonly used for conversion of FPP into squalene ( $h p n C, h p n D$, and $h p n E)$ but lack $h p n E$ (i.e., Acidobacteriaceae sp. KBS89) or both $h p n C$ and $h p n E$ (i.e., S. bohemicum S15, G. mallensis MP5ACTX8, Acidobacteriaceae sp. TAA66). Unfortunately, these strains were not tested for hopanoid production. However, phylogenetically closely related strains were (Figure 1), suggesting that they still would be able to produce hopanoids and, thus, squalene. Remarkably, in these strains, and in E. aggregans, a gene annotated as coding for farnesyl diphosphate farnesyl transferase ( $f d f T)$ was detected, but was absent in any of the other acidobacteria. This gene is somewhat comparable to the gene encoding for squalene synthase, an enzyme occurring in many eukaryotes, where it catalyzes two reactions, i.e., the coupling of two molecules of FPP to give PSPP and the subsequent NADPHdependent reductive rearrangement of PSPP to squalene without the release PSPP from the active site. A similar enzyme has been characterized in a cyanobacterium (Lee and Poulter, 2008) and a gammaproteobacterium (Ohtake et al., 2014). The FdfT enzymes in the acidobacteria show a sequence identity of ca. $30 \%$ with the characterized bacterial squalene synthases but the protein alignments (Figure S1) show that the active sites of the enzymes are more conserved, suggesting that the detected $f d f T$ genes encode an enzyme capable of direct conversion of two molecules of farnesyl diphosphate into squalene. The presence of both $h p n D$ and $f d f T$ in the acidobacteria that lack the $h p n C$ $h p n D-h p n E$ cassette may alternatively suggest that $f d f T$ encodes an enzyme that converts PSPP directly into squalene (Figure 4) but this hypothesis needs to be tested.

Remarkably, the fdf $T$ occurring in five acidobacterial species is phylogenetically closely related to $f d f T$ of several Parabulkholderia and Caballeronia species (Betaproteobacteria; Figure 6); the sequence identity at the protein level is ca. $70-80 \%$. This high level of sequence similarity suggests that lateral gene 
transfer has introduced this gene. Interestingly, some of the closely related species were isolated from soil (e.g., Caballeronia glathei, Zolg and Ottow, 1975; Paraburkholderia sartisoli, Vanlaere et al., 2008) and decaying wood (e.g., P. sordidicola; Lim et al., 2003), similar ecological niches as occupied by SD1 Acidobacteria, supporting the suggestion of horizontal gene transfer. Naumoff and Dedysh (2012) have previously recognized horizontal gene transfer between Bacteroidetes and Acidobacteria for genes encoding alfa-L-rhamnosidases and proposed that sharing a similar ecological niche facilitated such events. E. aggregans possesses even two copies of the fdfT gene in addition to the complete gene cluster A (Table 2). This is also one of the SD1 Acidobacteria with the largest genome size $(8.2 \mathrm{Mb}$; Table 2), which perhaps explains why it is carrying genes that seem not essential. Challacombe et al. (2011) suggested earlier for " $\mathrm{Ca}$. S. usitatus Ellin6076" that its relatively large genome (9.9.Mb; $2-5$ times as large as most other Acidobacteria) has arisen by horizontal gene transfer and widespread small-scale gene duplications, resulting in an increased number of paralogs.

\section{BHP Biosynthesis}

The synthesis of (composite) BHPs from squalene in bacteria is performed by a sequence of enzymatic reactions (Figure 3) for which quite a number of coding genes is known (Table S1). For the acidobacterial genomes studied, it is apparent that those that possess shc also contain $h p n H$ and $h p n G$ (Table 2), the genes encoding enzymes for the first two steps of the biosynthesis of BHT. The phylogeny of these proteins (like shc; Figure 5) is broadly similar to that of the $16 \mathrm{~S}$ rRNA gene, suggesting that these genes are inherited from a common ancestor. In all SD1 Acidobacteria (except for "Ca. K. versatilis Ellin345") $h p n H$ forms together with shc and ispH a gene cluster. "Ca. K. versatilis Ellin345" is also with respect to 16S rRNA gene phylogeny (Figure 1) the most remote species. In all SD1 and SD3 Acidobacteria, $h p n G$ forms a gene cluster with $h p n A$, which is present in all acidobacteria that possess $s h c, h p n H$, and $h p n G$, suggesting that it is essential for the formation of BHPs. It is annotated as a hopanoid-associated sugar epimerase. It may catalyze the step transformation of ribosyl hopanes to BHT (Figure 4) for which the enzyme is still unknown. However, Schmerk et al. (2015) presented some evidence that $h p n A$ was not essential for BHT synthesis in Burkholderia cenocepacia and some BHT producers (like Rhodopseudomonas) do not have a copy of hpnA in their genome (Welander et al., 2012).

BHT can subsequently be converted into composite BHPs such as BHT cyclitol ether (Figure 4). For this latter conversion three genes are required: $h p n I, h p n K$, and $h p n J$ (Table S1). The only SD4 acidobacterium capable of producing BHPs, $C$. thermophilum $\mathrm{B}$, is also the only acidobacterium that possesses all these genes (Table 2). In good agreement with this, intact BHP analysis of $C$. thermophilum B has revealed the biosynthesis of BHT cyclitol ether, in addition to BHT (Costas et al., 2012b). In contrast, the SD1 and SD3 Acidobacteria do possess $h p n J$ and $h p n I$ but lack $h p n K$ (Table 1), suggesting that they are not able to produce BHT cyclitol ether. Since the Rohmer degradation method transforms both BHT and its cyclitol ether derivative into homohopanol, our dataset does not allow confirming this point.
The $h p n O$ gene, encoding the enzyme responsible for the last step in the formation of amino bacteriohopanetriol from BHT (Figure 4) was detected in SD1 (but not all) and SD3 acidobacterial genomes, suggesting that these bacteria would be capable of producing amino bacteriohopanetriol.

\section{Methylation of Hopanoids in Acidobacteria}

Welander et al. (2010) and Welander and Summons (2012) previously reported the presence of the genes encoding the enzymes responsible for methylation of the A-ring of biohopanoids ( $h p n P$ and $h p n R$ ) in the genome of the acidobacterium "Ca. K. versatilis Ellin345." Methylated BHPs were indeed detected in cultures of " $\mathrm{Ca}$. K. versatilis Ellin345" in our study although the relative amounts were low and highly variable. Surprisingly, the Rohmer degradation products of the BHPs of " $\mathrm{Ca}$. K. versatilis Ellin345" contain a tentatively identified dimethylated homohopanol. To the best of our knowledge, hopanoids methylated at both position 2 and 3 have not been previously encountered. However, its presence is consistent with the presence of both the $h p n P$ and $h p n R$ methylation genes, which is very rare in the bacterial domain. The only other bacterial genome in the NCBI database that possesses these two genes is Methylobacterium nodulans ORS2060 (Marx et al., 2012), a soil bacterium growing on $C_{1}$ compounds belonging to the Alphaproteobacteria (Jourand et al., 2004). The dimethylated BHPs only occurred in one of the three batch cultures of " $\mathrm{Ca}$. K. versatilis Ellin345" examined. We tentatively attribute this to the growth phase in which the culture was harvested. It has been demonstrated for $M$. capsulatus that 3-methylhopanoids appear to be required for the maintenance of intracytoplasmic membranes and cell survival in late stationary phase (Welander and Summons, 2012). Consequently, methylated BHPs may be primarily formed in this stage of the growth curve but this will require further research.

Remarkably, only one of the many investigated acidobacterial species produces or has potential genetic capacity to produce methylated BHPs. For the acidobacterial environmental genomes studied also no evidence for production of methylated BHPs was obtained, even though some genomes were closely related to " $\mathrm{Ca}$. K. versatilis Ellin345" (Figure 1). This has been observed for other bacterial phyla; Welander and Summons (2012) reported that only 3 out of 38 Burkholderia, 8 out of 43 Streptomyces, and 1 out 8 Methylobacterium genomes harbored the $h p n R$ gene, while all possessed the shc gene. Also for the $h p n P$ gene it has been observed that only a limited number of species of a bacterial phylum (e.g., Cyanobacteria) possess this gene (Welander et al., 2010). This poses questions on the evolutionary origin of these methylases. For the Acidobacteria it seems rather unlikely that their common ancestor possessed both genes and all but one of the examined species (i.e., "Ca. K. versatilis Ellin345”) lost them. It seems, therefore, much more plausible that " $\mathrm{Ca}$. $\mathrm{K}$. versatilis Ellin 345 " obtained these genes through horizontal gene transfer, although both $h p n P$ and $h p n R$ gene of "Ca. K. versatilis Ellin 345 " are not closely related to any other in other bacterial phyla, a situation that is clearly different from the case observed for the $f d f T$ gene (see above and Figure 6). Ricci et al. (2015) concluded that the $h p n P$ gene originated in a subset 
of the Alphaproteobacteria and that it was likely horizontally transferred into the Cyanobacteria after their major divergences, providing further evidence that the ancestral function of 2methylhopanoids was not related to oxygenic photosynthesis (cf. Summons et al., 1999). They also concluded from their analysis that at approximately the same time as the horizontal hpnP gene transfer event between Alphaproteobacteria and Cyanobacteria, $h p n P$ appears to have been laterally transferred to the Acidobacteria. This ancient horizontal gene transfer would explain why the $h p n P$ gene of “ $\mathrm{Ca}$. K. versatilis Ellin345" is not closely related to any other $h p n P$ gene in other bacterial phyla. However, it remains enigmatic why " $\mathrm{Ca}$. K. versatilis Ellin345" is the only acidobacterium carrying this gene, a situation, which is clearly distinct from that in the Cyanobacteria where many species possess the hpnP gene (Ricci et al., 2015).

\section{Implications for BHPs in the Environment}

BHPs are omnipresent biomarkers that are being used for a wide variety of applications. Environmental microbiology studies using 16S rRNA or functional genes (e.g., shc and $h p n R$ ) have been applied to trace potential sources of BHPs in the environment (e.g., Pearson et al., 2007; Coolen et al., 2008; Ricci et al., 2014). However, culture studies remain essential for a proper understanding of sources of BHPs in the environment. This study provides for the first time a comprehensive overview of the occurrence of BHPs in Acidobacteria. Our results indicate that, in the phylogenetic groups investigated, BHP biosynthesis is mostly limited to SDs 1, 2, and 3 and a closely affiliated group (SD1/3), out of the many SDs of the phylum. This may suggest that in the environment Acidobacteria may not be considered as important sources of BHPs. However, many studies have indicated that SD1, 2, and 3 Acidobacteria are among the most abundant acidobacterial groups in wetlands and soil, whereas SD1 members thrive in lakes (see Kielak et al., 2016 for a recent review). Furthermore, Acidobacteria often form an important fraction of the bacterial community in soils and peat bogs (e.g., Chan et al., 2006; Weijers et al., 2009; i.e., up to 80\%). Therefore, in a wide variety of environments acidobacteria could, despite the somewhat restricted BHP biosynthetic capacity in the phylum as a whole, still be considered potentially quantitatively important $\mathrm{BHP}$ producers in the environment.

Methylated BHPs are considered to be even better constrained biomarkers in the environment, although this has been

\section{REFERENCES}

Abascal, F., Zardoya, R., and Posada, D. (2005). ProtTest: selection of best-fit models of protein evolution. Bioinformatics 21, 2104-2105. doi: 10.1093/bioinformatics/bti263

Anantharaman, K., Brown, C. T., Hug, L. A., Sharon, I., Castelle, C. J., Probst, A. J., et al. (2016). Thousands of microbial genomes shed light on interconnected biogeochemical processes in an aquifer system. Nat. Commun. 7:13219. doi: $10.1038 /$ ncomms13219

Barns, S. M., Cain, E. C., Sommerville, L., and Kuske, C. R. (2007). Acidobacteria phylum sequences in uranium-contaminated subsurface sediments greatly expand the known diversity within the phylum. Appl. Environ. Microbiol. 73, 3113-3116. doi: 10.1128/AEM.02012-06 challenged by genomic (Welander et al., 2010; Welander and Summons, 2012; Ricci et al., 2015) and environmental microbiological (Ricci et al., 2014) studies. These authors also discovered the methylation genes of the BHP pathway in "Ca. K. versatilis Ellin345" and this study confirmed that this species under certain conditions produces small amounts of a dimethylated BHP. However, "Ca. K. versatilis Ellin345" is the only acidobacterium identified so far that is able to produce methylated hopanoids and, therefore, Acidobacteria are unlikely to play an important role in sourcing methylated BHPs in the environment.

\section{AUTHOR CONTRIBUTIONS}

JD and LV generated hypothesis and planned experiments. LV, $\mathrm{SD}$, and BF have grown cultures. WR performed lipid analyses and JD and WR interpreted the data. JD and LV analyzed genome data, interpreted the data and wrote the paper. All other authors provided comments on the text.

\section{FUNDING}

This project received funding from the European Research Council (ERC) under the European Union's Horizon 2020 research and innovation program (grant agreement $\mathrm{n}^{\circ} 694569-$ MICROLIPIDS). JD receives funding from the Soehngen Institute for Anaerobic Microbiology (SIAM) though a gravitation grant from the Dutch ministry for Education, Culture and Science (grant number 024.002.002). SD is supported by the Russian Science Foundation (project no. 16-14-10210).

\section{ACKNOWLEDGMENTS}

We thank Drs. P. Dunfield, M. Stott, D. Bryant, S. Nagakawa, K. J. Huber, and P. A. Lawson for cell material, D. Kool for analytical assistance, and the two referees for helpful comments.

\section{SUPPLEMENTARY MATERIAL}

The Supplementary Material for this article can be found online at: http://journal.frontiersin.org/article/10.3389/fmicb. 2017.00968/full\#supplementary-material 
methylotrophy and archaeal heterotrophy are prevalent below the grass root zone. PeerJ 4:e2687. doi: 10.7717/peerj.2687

Challacombe, J. F., Eichorst, S. A., Hauser, L., Land, M., Xie, G., and Kuske, C. R. (2011). Biological consequences of ancient gene acquisition and duplication in the large genome of Candidatus Solibacter usitatus Ellin6076. PLoS ONE 6:e24882. doi: 10.1371/journal.pone.0024882

Chan, O. C., Yang, X. D., Fu, Y., Feng, Z. L., Sha, L. Q., Casper, P., et al. (2006). 16 S rRNA gene analyses of bacterial community structures in the soils of evergreen broad-leaved forests in south-west China. FEMS Microb. Ecol. 58, 247-259. doi: 10.1111/j.1574-6941.2006.00156.x

Coates, J. D., Ellis, D. J., Gaw, C. V., and Lovley, D. R. (1999). Geothrix fermentans gen. nov., sp nov., a novel $\mathrm{Fe}(\mathrm{III})$-reducing bacterium from a hydrocarbon-contaminated aquifer. Int. J. Syst. Bacteriol. 49, 1615-1622. doi: 10.1099/00207713-49-4-1615

Coolen, M. J., Talbot, H. M., Abbas, B. A., Ward, C., Schouten, S., Volkman, J. K., et al. (2008). Sources for sedimentary bacteriohopanepolyols as revealed by $16 \mathrm{~S}$ rDNA stratigraphy. Environ. Microbiol. 10, 1783-1803. doi: 10.1111/j.1462-2920.2008.01601.x

Costas, A. M. G., Amaya, M., Liu, Z., Tomsho, L. P., Schuster, S. C., Ward, D. M., et al. (2012a). Complete genome of Candidatus Chloracidobacterium thermophilum, a chlorophyll-based photoheterotroph belonging to the phylum. Acidobacteria. Environ. Microbiol. 14, 177-190. doi: 10.1111/j.1462-2920.2011.02592.x

Costas, A. M. G., Tsukatani, Y., Rijpstra, W. I. C., Schouten, S., Welander, P. V., Summons, R. E., et al. (2012b). Identification of the bacteriochlorophylls, carotenoids, quinones, lipids, and hopanoids of “Candidatus Chloracidobacterium thermophilum." J. Bacteriol. 194, 1158-1168. doi: 10.1128/JB.06421-11

Crowe, M. A., Power, J. F., Morgan, X. C., Dunfield, P. F., Lagutin, K., Rijpstra, W. I. C., et al. (2014). Pyrinomonas alimethylogenes gen. nov. sp. nov., a novel group 4 thermophilic Acidobacteria from geothermal soils. Int. J. Syst. Evol. Microbiol. 64, 220-227. doi: 10.1099/ijs.0.055079-0

Dedysh, S. N., Kulichevskaya, I. S., Serkebaeva, Y. M., Mityaeva, M. A., Sorokin, V. V., Suzina, N. E., et al. (2012). Bryocella elongata gen. nov., sp. nov., a member of subdivision 1 of the Acidobacteria isolated from a methanotrophic enrichment culture, and emended description of Edaphobacter aggregans Koch et al. (2008). Int. J. Syst. Evol. Microbiol. 62, 654-664. doi: 10.1099/ijs.0.031898-0

Dedysh, S. N., Pankratov, T. A., Belova, S. E., Kulichevskaya, I. S., and Liesack, W. (2006). Phylogenetic analysis and in situ identification of Bacteria community composition in an acidic Sphagnum peat bog. Appl. Environ. Microbiol. 72, 2110-2117. doi: 10.1128/AEM.72.3.2110-2117.2006

Edgar, R. C. (2004). MUSCLE: a multiple sequence alignment method with reduced time and space complexity. BMC Bioinformatics 5:113. doi: 10.1186/1471-2105-5-113

Eichorst, S. A., Breznak, J. A., and Schmidt, T. M. (2007). Isolation and characterization of soil bacteria that define Terriglobus gen. nov., in the phylum Acidobacteria. Appl. Environ. Microbiol. 73, 2708-2717. doi: 10.1128/AEM.02140-06

Felsenstein, J. (1985). Confidence limits on phylogenies: an approach using the bootstrap. Evolution 39, 783-791. doi: 10.2307/2408678

Foesel, B. U., Rohde, M., and Overmann, J. (2013). Blastocatella fastidiosa gen. nov., sp nov., isolated from semiarid savanna soil - the first described species of Acidobacteria subdivision 4. Syst. Appl. Microbiol. 36, 82-89. doi: 10.1016/j.syapm.2012.11.002

Foesel, B. U., Mayer, S., Luckner, M., Wanner, G., Rohde, M., and Overmann, J. (2016). Occallatibacter riparius gen. nov., sp. nov. and Occallatibacter savannae sp. nov., acidobacteria isolated from Namibian soils, and emended description of the family Acidobacteriaceae. Int. J. Syst. Evol. Microbiol. 66, 219-229. doi: 10.1099/ijsem.0.000700

Guindon, S., Dufayard, J. F., Lefort, V., Anisimova, M., Hordijk, W., and Gascuel, O. (2010). New algorithms and methods to estimate maximum-likelihood phylogenies: assessing the performance of PhyML 3.0. Syst. Biol. 59, 307-321. doi: 10.1093 /sysbio/syq010

Huber, K. J., Geppert, A. M., Wanner, G., Fösel, B. U., Wüst, P. K., and Overmann, J. (2016). The first representative of the globally widespread subdivision Acidobacteria, Vicinamibacter silvestris gen. nov., sp. nov., isolated from subtropical savannah soil. Int. J. Syst. Evol. Microbiol. 66, 2971-2979. doi: 10.1099/ijsem.0.001131
Huber, K. J., Wüst, P. K., Rohde, M., Overmann, J., and Foesel, B. U. (2014). Aridibacter famidurans gen. nov., sp. nov. and Aridibacter kavangonensis sp. nov., two novel members of subdivision 4 of the Acidobacteria isolated from semiarid savannah soil. Int. J. Syst. Evol. Microbiol. 64, 1866-1875. doi: 10.1099/ijs.0.060236-0

Izumi, H., Nunoura, T., Miyazaki, M., Mino, S., Toki, T., Takai, K. et al. (2012). Thermotomaculum hydrothermale gen. nov., sp nov., a novel heterotrophic thermophile within the phylum Acidobacteria from a deep-sea hydrothermal vent chimney in the Southern Okinawa Trough. Extremophiles 16, 245-253. doi: 10.1007/s00792-011-0425-9

Janssen, P. H. (2006). Identifying the dominant soil bacterial taxa in libraries of 16S rRNA and 16S rRNA genes. Appl. Environ. Microbiol. 72, 1719-1728. doi: 10.1128/AEM.72.3.1719-1728.2006

Jones, R. T., Robeson, M. S., Lauber, C. L., Hamady, M., Knight, R., Fierer, N. (2009). A comprehensive survey of soil acidobacterial diversity using pyrosequencing and clone library analyses. ISME J. 3, 442-453. doi: 10.1038/ismej.2008.127

Joseph, S. J., Hugenholtz, P., Sangwan, P., Osborne, C. A., and Janssen, P. H. (2003). Laboratory cultivation of widespread and previously uncultured soil bacteria. Appl. Environm. Microbiol. 69, 7210-7215. doi: 10.1128/AEM.69.12.7210-7215.2003

Jourand, P., Giraud, E., Béna, G., Sy, A., Willems, A., Gillis, M., et al. (2004). Methylobacterium nodulans sp. nov., for a group of aerobic, facultatively methylotrophic, legume root-nodule-forming and nitrogen-fixing bacteria. Int. J. Syst. Evol. Microbiol. 54, 2269-2273. doi: 10.1099/ijs.0.02902-0

Jukes, T. H., and Cantor, C. R. (1969). "Evolution of protein molecules," in Mammalian Protein Metabolism, ed H. N. Munro (New York, NY: Academic Press), 21-132.

Kannenberg, E. L., and Poralla, K. (1999). Hopanoid biosynthesis and function in bacteria. Naturwissenschaften 86, 168-176. doi: 10.1007/s001140050592

Kielak, A. M., Barreto, C. C., Kowalchuk, G. A., van Veen, J. A., and Kuramae, E. E. (2016). The ecology of Acidobacteria: moving beyond genes and genomes. Front. Microbiol. 7:744. doi: 10.3389/fmicb.2016.00744

Kishimoto, N., Kosako, Y., and Tano, T. (1991). Acidobacterium capsulatum gen. nov, sp. nov. - an acidophilic chemoorganotrophic bacterium containing menaquinone from acidic mineral environment. Curr. Microbiol. 22, 1-7. doi: 10.1007/BF02106205

Knani, M. H., Corpe, W. A., and Rohmer, M. (1994). Bacterial hopanoids from pink-pigmented facultative methylotrophs (PPFMs) and from green plant surfaces. Microbiology 140, 2755-2759. doi: 10.1099/00221287-140-10-2755

Koch, I. H., Gich, F., Dunfield, P. F., and Overmann, J. (2008). Edaphobacter modestus gen. nov., sp nov., and Edaphobacter aggregans sp nov., acidobacteria isolated from alpine and forest soils. Int. J. Syst. Evol. Microbiol. 58, 1114-1122. doi: 10.1099/ijs.0.65303-0

Kulichevskaya, I. S., Kostina, L. A., Valaskova, V., Rijpstra, W. I. C., Sinninghe Damsté, J. S., de Boer, W. T., et al. (2012). Acidicapsa borealis gen. nov., sp. nov and Acidicapsa ligni sp nov., subdivision 1 Acidobacteria from Sphagnum peat and decaying wood. Int. J. Syst. Evol. Microbiol. 62, 1512-1520. doi: 10.1099/ijs.0.034819-0

Kulichevskaya, I. S., Suzina, N. E., Liesack, W., and Dedysh, S. N. (2010). Bryobacter aggregatus gen. nov., sp nov., a peat-inhabiting, aerobic chemoorganotroph from subdivision 3 of the Acidobacteria. Int. J. Syst. Evol. Microbiol. 60, 301-306. doi: 10.1099/ijs.0.013250-0

Kulichevskaya, I. S., Suzina, N. E., Rijpstra, W. I. C., Sinninghe Damsté, J. S., and Dedysh, S. N. (2014). Paludibaculum fermentans gen. nov., sp. nov., a facultative anaerobe capable of dissimilatory iron reduction from subdivision 3 of the Acidobacteria. Int. J. Syst. Evol. Microbiol. 64, 2857-2864. doi: 10.1099/ijs.0.066175-0

Kuypers, M. M., van Breugel, Y., Schouten, S., Erba, E., and Sinninghe Damsté, J. S. (2004). $\mathrm{N}_{2}$-fixing cyanobacteria supplied nutrient $\mathrm{N}$ for Cretaceous oceanic anoxic events. Geology 32, 853-856. doi: 10.1130/G20458.1

Lee, S., and Poulter, C. D. (2008). Cloning, solubilization, and characterization of squalene synthase from Thermosynechococcus elongatus BP-1. J. Bacteriol. 190, 3808-3816. doi: 10.1128/JB.01939-07

Liesack, W., Bak, F., Kreft, J.-U., and Stackebrandt, E. (1994). Holophaga foetida gen. nov., sp. nov., a new, homoacetogenic bacterium degrading methoxylated aromatic compounds. Arch. Microbiol. 162, 85-90. doi: 10.1007/bf00 264378 
Lim, Y. W., Baik, K. S., Han, S. K., Kim, S. B., and Bae, K. S. (2003). Burkholderia sordidicola sp. nov., isolated from the white-rot fungus Phanerochaete sordida. Int. J. Syst. Evol. Microbiol. 53, 1631-1636. doi: 10.1099/ijs.0.02456-0

Losey, N. A., Stevenson, B. S., Busse, H. J., Sinninghe Damsté, J. S., Rijpstra, W. I. C., Rudd, I. S., et al. (2013). Thermoanaerobaculum aquaticum gen. nov., sp. nov., the first cultivated member of Acidobacteria subdivision 23, isolated from a hot spring. Int. J. Syst. Evol. Microbiol. 63, 4149-4157. doi: 10.1099/ijs.0.051425-0

Marx, C. J., Bringel, F., Chistoserdova, L., Moulin, L., Haque, M. F. U., Fleischman, D. E., et al. (2012). Complete genome sequences of six strains of the genus Methylobacterium. J. Bacteriol. 194:4746. doi: 10.1128/JB.01009-12

Naumoff, D. G., and Dedysh, S. N. (2012). Lateral gene transfer between the Bacteroidetes and Acidobacteria: the case of $\alpha$-L-rhamnosidases. FEBS Lett. 586, 3843-3851. doi: 10.1016/j.febslet.2012.09.005

Neubauer, C., Dalleska, N. F., Cowley, E. S., Shikuma, N. J., Wu, C. H., Sessions, A. L., et al. (2015). Lipid remodeling in Rhodopseudomonas palustris TIE-1 upon loss of hopanoids and hopanoid methylation. Geobiology 13, 443-453. doi: $10.1111 /$ gbi.12143

Ohtake, K., Saito, N., Shibuya, S., Kobayashi, W., Amano, R., Hirai, T., et al. (2014). Biochemical characterization of the water-soluble squalene synthase from Methylococcus capsulatus and the functional analyses of its two DXXD (E) D motifs and the highly conserved aromatic amino acid residues. FEBS J. 281, 5479-5497. doi: 10.1111/febs.13090

Ourisson, G., Albrecht, P., and Rohmer, M. (1979). The hopanoids: palaeochemistry and biochemistry of a group of natural products. Pure Appl. Chem. 51, 709-729. doi: 10.1351/pac197951040709

Pan, J. J., Solbiati, J. O., Ramamoorthy, G., Hillerich, B. S., Seidel, R. D., Cronan, J. E., et al. (2015). Biosynthesis of squalene from farnesyl diphosphate in bacteria: three steps catalyzed by three enzymes. ACS Central Sci. 1, 77-82. doi: 10.1021/acscentsci.5b00115

Pankratov, T. A. (2012). Acidobacteria in microbial communities of the bog and tundra lichens. Microbiology 81, 51-58. doi: 10.1134/S0026261711060166

Pankratov, T. A., and Dedysh, S. N. (2010). Granulicella paudicola gen. nov., sp. nov., Granulicella pectinivorans sp. nov., Granulicella aggregans sp. nov. and Granulicella rosea sp. nov., acidophilic, plymers-degrading acidobacteria from Sphagnum peat bogs. Int. J. Syst. Evol. Microbiol. 60, 2951-2959. doi: 10.1099/ijs.0.021824-0

Pankratov, T. A., Kirsanova, L. A., Kaparullina, E. N., Kevbrin V. V., and Dedysh, S. N. (2012). Telmatobacter bradus gen. nov., sp. nov., a cellulolytic facultative anaerobe from subdivision 1 of the Acidobacteria, and emended description of Acidobacterium capsulatum Kishimoto et al. 1991. Int. J. Syst. Evol. Microbiol. 62, 430-437. doi: 10.1099/ijs.0.029629-0

Pankratov, T. A., Serkebaeva, Y. M., Kulichevskaya, I. S., Liesack, W., and Dedysh, S. N. (2008). Substrate-induced growth and isolation of Acidobacteria from acidic Sphagnum peat. ISME J. 2, 551-560. doi: 10.1038/ismej.2008.7

Pascual, J., Wüst, P. K., Geppert, A., Foesel, B. U., Huber, K. J., and Overmann, J. (2015). Novel isolates double the number of chemotrophic species and allow the first description of higher taxa in Acidobacteria subdivision 4. Syst. Appl. Microbiol. 38, 534-544. doi: 10.1016/j.syapm.2015.08.001

Pearson, A., Flood Page, S. R., Jorgenson, T. L., Fischer, W. W., and Higgins, M. B. (2007). Novel hopanoid cyclases from the environment. Environ. Microbiol. 9, 2175-2188. doi: 10.1111/j.1462-2920.2007.01331.x

Pearson, A., Leavitt, W. D., Sáenz, J. P., Summons, R. E., Tam, M. C. M., and Close, H. G. (2009). Diversity of hopanoids and squalene-hopene cyclases across a tropical land-sea gradient. Environ. Microbiol. 11, 1208-1223. doi: 10.1111/j.1462-2920.2008.01817.x

Perzl, M., Reipen, I. G., Schmitz, S., Poralla, K., Sahm, H., Sprenger, G. A., et al. (1998). Cloning of conserved genes from Zymomonas mobilis and Bradyrhizobium japonicum that function in the biosynthesis of hopanoid lipids. Biochim. Biophys. Acta 1393, 108-118. doi: 10.1016/S0005-2760(98)00064-2

Rashby, S. E., Sessions, A. L., Summons, R. E., and Newman, D. K. (2007). Biosynthesis of 2-methylbacteriohopanepolyols by an anoxygenic phototroph. Proc. Nat. Acad. Sci. U.S.A. 104, 15099-15104. doi: 10.1073/pnas.070 4912104

Rezanka, T., Siristova, L., Melzoch, K., and Sigler, K. (2010). Hopanoids in bacteria and cyanobacteria-their role in cellular biochemistry and physiology, analysis and occurrence. Mini Rev. Organ. Chem. 7, 300-313. doi: $10.2174 / 157019310792246436$
Ricci, J. N., Coleman, M. L., Welander, P. V., Sessions, A. L., Summons, R. E., Spear, J. R., et al. (2014). Diverse capacity for 2-methylhopanoid production correlates with a specific ecological niche. ISME J. 8, 675-684. doi: 10.1038/ismej.2013.191

Ricci, J. N., Michel, A. J., and Newman, D. K. (2015). Phylogenetic analysis of HpnP reveals the origin of 2-methylhopanoid production in Alphaproteobacteria. Geobiology 13, 267-277. doi: 10.1111/gbi.12129

Rohmer, M., Bouvier-Nave, P., and Ourisson, G. (1984). Distribution of hopanoid triterpenes in prokaryotes. Microbiology 130, 1137-1150. doi: 10.1099/00221287-130-5-1137

Saitou, N., and Nei, M. (1987). The neighbor-joining method: a new method for reconstructing phylogenetic trees. Mol. Biol. Evol. 406-425.

Sauret-Güeto, S., Urós, E. M., Ibáñez, E., Boronat, A., and Rodríguez-Concepción, M. (2006). A mutant pyruvate dehydrogenase E1 subunit allows survival of Escherichia coli strains defective in 1-deoxy-d-xylulose 5-phosphate synthase. FEBS Lett. 580, 736-740. doi: 10.1016/j.febslet.2005.12.092

Schmerk, C. L., Welander, P. V., Hamad, M. A., Bain, K. L., Bernards, M. A., Summons, R. E., et al. (2015). Elucidation of the Burkholderia cenocepacia hopanoid biosynthesis pathway uncovers functions for conserved proteins in hopanoid-producing bacteria. Environ. Microbiol. 17, 735-750. doi: 10.1111/1462-2920.12509

Serkebaeva, Y. M., Kim, Y., Liesack, W., and Dedysh, S. N. (2013). Pyrosequencingbased assessment of the bacteria diversity in surface and subsurface peat layers of a northern wetland, with focus on poorly studied phyla and candidate divisions. PLoS ONE 8:e63994. doi: 10.1371/journal.pone.0063994

Sinninghe Damsté, J. S., Rijpstra, W. I. C., Hopmans, E. C., Foesel, B. U., Wüst, P. K., Overmann, J., et al. (2014). Ether- and ester-bound iso-diabolic acid and other lipids in members of Acidobacteria subdivision 4. Appl. Environ. Microbiol. 80, 5207-5218. doi: 10.1128/AEM.01066-14

Sinninghe Damsté, J. S., Rijpstra, W. I. C., Hopmans, E. C., Weijers, J. W. H., Foesel, B. U., Overmann, J., et al. (2011). 13,16-dimethyl octacosanedioic acid (iso-diabolic acid), a common membrane-spanning lipid of Acidobacteria subdivisions 1 and 3. Appl. Environ. Microbiol. 77, 4147-4154. doi: 10.1128/AEM.00466-11

Speth, D. R., Guerrero-Cruz, S., Dutilh, B. E., and Jetten, M. S. M. (2016). Genome-based microbial ecology of anammox granules in a full-scale wastewater treatment system. Nat. Commun. 7:11172. doi: 10.1038/ncomms 11172

Summons, R. E., Jahnke, L. L., Hope, J. M., and Logan, G. A. (1999). 2Methylhopanoids as biomarkers for cyanobacterial oxygenic photosynthesis. Nature 400, 554-557. doi: 10.1038/23005

Tamura, K., Stecher, G., Peterson, D., Filipski, A., and Kumar, S. (2013). MEGA6: molecular evolutionary genetics analysis version 6.0. Mol. Biol. Evol. 30, 2725-2729. doi: 10.1093/molbev/mst197

Tank, M., and Bryant, D. A. (2015). Chloracidobacterium thermophilum gen. nov., sp. nov.: an anoxygenic microaerophilic chlorophotoheterotrophic acidobacterium. Int. J. Syst. Evol. Microbiol. 65, 1426-1430. doi: 10.1099/ijs.0.000113

Thompson, J. D., Higgins, D. G., and Gibson, T. J. (1994). CLUSTAL W: improving the sensitivity of progressive multiple sequence alignment through sequence weighting, position-specific gap penalties and weight matrix choice. Nucl. Acids Res. 22, 4673-4680. doi: 10.1093/nar/22.22.4673

Vanlaere, E., van der Meer, J., Falsen, E., Salles, J. F., de Brandt, E., and Vandamme, P. (2008). Burkholderia sartisoli sp. nov., isolated from a polycyclic aromatic hydrocarbon-contaminated soil. Int. J. Syst. Evol. Microbiol. 58, 420-423. doi: 10.1099/ijs.0.65451-0

Vieira, S., Luckner, M., Wanner, G., and Overmann, J. (2017). Luteitalea pratensis gen. nov., sp. nov. a new member of subdivision 6 Acidobacteria isolated from temperate grassland soil. Int. J. Syst. Evol. Microbiol. doi: 10.1099/ijsem.0.001827. [Epub ahead of print].

Vilcheze, C., Llopiz, P., Neunlist, S., Poralla, K., and Rohmer, M. (1994). Prokaryotic triterpenoids: new hopanoids from the nitrogen-fixing bacteria Azotobacter vinelandii, Beijerinckia indica and Beijerinckia mobilis. Microbiology 140, 2749-2753. doi: 10.1099/00221287-14010-2749

Ward, N. L., Challacombe, J. F., Janssen, P. H., Henrissat, B., Coutinho, P. M., Wu, M., et al. (2009). Three genomes from the phylum Acidobacteria provide insight into the lifestyles of these microorganisms in soils. Appl. Environm. Microbiol. 75, 2046-2056. doi: 10.1128/AEM.02294-08 
Weijers, J. W., Panoto, E., van Bleijswijk, J., Schouten, S., Rijpstra, W. I. C., Balk, M., et al. (2009). Constraints on the biological source(s) of the orphan branched tetraether membrane lipids. Geomicrobiol. J. 26, 402-414. doi: $10.1080 / 01490450902937293$

Welander, P. V., and Summons, R. E. (2012). Discovery, taxonomic distribution, and phenotypic characterization of a gene required for 3methylhopanoid production. Proc. Nat. Acad. Sci. U.S.A. 109, 12905-12910. doi: 10.1073/pnas.1208255109

Welander, P. V., Coleman, M. L., Sessions, A. L., Summons, R. E., and Newman, D. K. (2010). Identification of a methylase required for 2-methylhopanoid production and implications for the interpretation of sedimentary hopanes. Proc. Nat. Acad. Sci. U.S.A. 107, 8537-8542. doi: 10.1073/pnas.0912949107

Welander, P. V., Doughty, D. M., Wu, C. H., Mehay, S., Summons, R. E., and Newman, D. K. (2012). Identification and characterization of Rhodopseudomonas palustris TIE-1 hopanoid biosynthesis mutants. Geobiology 10, 163-177. doi: 10.1111/j.1472-4669.2011.00314.x

Wüst, P. K., Foesel, B. U., Geppert, A., Huber, K. J., Luckner, M., Wanner, G., et al. (2016). Brevitalea aridisoli, B. deliciosa, and Arenimicrobium luteum, three novel species of Acidobacteria subdivision 4 (class Blastocatellia) isolated from Namibian savanna soil and description of the novel family Pyrinomonadaceae. Int. J. Syst. Evol. Microbiol. 66, 3355-3366, doi: 10.1099/ijsem.0.001199

Yanai, I., Derti, A., and DeLisi, C. (2001). Genes linked by fusion events are generally of the same functional category: a systematic analysis of 30 microbial genomes. Proc. Nat. Acad. Sci. U.S.A. 98, 7940-7945. doi: $10.1073 /$ pnas. 141236298
Zhao, L., Chang, W. C., Xiao, Y., Liu, H. W., and Liu, P. (2013). Methylerythritol phosphate pathway of isoprenoid biosynthesis. Ann. Rev. Biochem. 82, 497-530. doi: 10.1146/annurev-biochem-052010-100934

Zimmermann, J., Portillo, M. C., Serrano, L., Ludwig, W., and Gonzalez, J. M. (2012). Acidobacteria in freshwater ponds at Donana National Park, Spain. Microb. Ecol. 63, 844-855. doi: 10.1007/s00248-011-9988-3

Zolg, W., and Ottow, J. C. G. (1975). Pseudomonas glathei sp. nov., a new nitrogen-scavenging rod isolated from acid lateritic relicts in Germany. Z. Allg. Mikrobiol. 15, 287-299. doi: 10.1002/jobm.3630150410

Zundel, M., and Rohmer, M. (1985). Prokaryotic triterpenoids. 3. The biosynthesis of 2B-methylhopanoids and 3ß-methylhopanoids of Methylobacterium organophilum and Acetobacter pasteurianus ssp. pasteurianus. Eur. J. Biochem. 150, 35-39. doi: 10.1111/j.1432-1033.1985.tb08984.x

Conflict of Interest Statement: The authors declare that the research was conducted in the absence of any commercial or financial relationships that could be construed as a potential conflict of interest.

Copyright (® 2017 Damsté, Rijpstra, Dedysh, Foesel and Villanueva. This is an openaccess article distributed under the terms of the Creative Commons Attribution License (CC BY). The use, distribution or reproduction in other forums is permitted, provided the original author(s) or licensor are credited and that the original publication in this journal is cited, in accordance with accepted academic practice. No use, distribution or reproduction is permitted which does not comply with these terms. 